\title{
Using Connected Vehicles in Variable Speed Limit Systems: System Design and Effects
}

Ellen F. Grumert 
Using connected vehicles in variable speed limit systems: System design and effects Ellen F. Grumert

Linköping Studies in Science and Technology. Dissertations, No. 1919

Copyright $\odot 2018$ Ellen F. Grumert, unless otherwise noted ISBN 978-91-7685-341-2

ISSN $0345^{-7524}$

Printed by LiU Tryck, Linköping, Sweden 2018 


\section{Abstract}

Motorway traffic management systems are useful for improving the traffic conditions on urban motorways. One of the most common motorway traffic management systems are variable speed limit systems. These systems adapt the speed limits based on the prevailing traffic conditions measured by roadside detectors and recommended or compulsory speed limits are shown on variable message signs installed on gantries over the road. The systems consist of three parts; the control algorithm used to determine which speed limit to be displayed, a method for estimating the traffic conditions to be used as input for the control algorithm and the infrastructure for application of the variable speed limits. The goal of the systems is often to increase safety or efficiency.

Recent development in the field of connected vehicles have opened up for a new type of data source, as the status of a connected vehicle and its surroundings can be communicated at arbitrary locations. Hence, by the use of connected vehicles in variable speed limit systems there is a potential of reducing the amount of roadside equipment. It is even possible to control the connected vehicles towards the current speed limit without the use of variable message signs. This allows for the application of variable speed limits at arbitrary locations.

The aim of this thesis is to examine how connected vehicles can be used to improve the efficiency of variable speed limit systems. The thesis contribute with new and improved methods using connected vehicles in all three parts of a variable speed limit system. The suggested methods are evaluated by microscopic traffic simulation. The overall 
conclusion is that the use of connected vehicles in variable speed limit systems can contribute to improvements in traffic efficiency compared to existing systems.

The six papers included in the thesis can be summarized as follows. First, it is shown that traditional variable speed limit systems can be effective for improving the traffic conditions on the motorway and the results can be comparable to more costly alterations by reconstruction of the infrastructure to increase the capacity. Next, the usefulness of connected vehicles for application and control of the speed limits in an existing variable speed limit system is investigated. It is concluded that the design of the control algorithm and the accuracy of the estimated traffic conditions have a great effect on the final outcome of the system. The design of the control algorithm is then examined by evaluation of a number of control algorithms with respect to safety, efficiency and environmental impacts. The main benefits and drawbacks of the algorithms are highlighted and desirable characteristics to include when designing a control algorithm are identified. In two studies, methods making use of connected vehicles for estimating the traffic conditions are proposed. The results show that connected vehicles are useful for improving the accuracy of the estimated traffic conditions through the inclusion of more detailed information and information at locations where detector measurements are not available. Finally, a variable speed limit system is proposed in which connected vehicles play a central role in the estimation of the traffic conditions, as well as in the control algorithm and for application of the speed limit. The system is shown to be useful for improving traffic efficiency during an incident at an arbitrary location along the controlled road. 


\section{Populärvetenskaplig sammanfattning}

Trafikstockning och olyckor som följd av tät trafik är vanliga på dagens motorvägar och speciellt vid rusningstrafik då många fordon befinner sig på vägen. I takt med att tekniken för att informera förare samt för att mäta trafikförhållanden utvecklats, har flera system tagits fram för att förbättra trafikförhållandena på motorvägar med avseende på framkomlighet och säkerhet. Ett av dagens vanligaste system i motorvägsmiljö bygger på variabla hastigheter och kallas variabla hastighetsstyrningssystem. Det innebär att den skyltade hastigheten anpassas till rådande trafikförhållanden. För att avgöra vilken hastighet som är bäst lämpad behöver man en uppskattning av de nuvarande trafikförhållandena. Det innebär att uppmätt trafikdata bearbetas för att få en bild av nuvarande medelhastighet, antalet fordon på vägen, och så vidare. Uppskattningen av trafikförhållandena används som ingångsvärde i en så kallad styralgoritm. En styralgoritm är en matematisk modell som beräknar den hastighet som bäst speglar målet med systemet genom att till exempel sänka hastigheten under trafikstockning för att öka framkomligheten eller säkerheten. Information om nuvarande hastighetsgränser delges sedan förare eller fordon. I dagens system samlas trafikdata ofta in med hjälp av detektorer längs vägen och hastigheter visas på variabla meddelandeskyltar över vägen.

I och med introduktionen av fordon med ständig internetuppkoppling, så kallade uppkopplade fordon, kan man få tillgång till mer 
detaljerad information om trafiken och dessutom är man oberoende av var de fasta detektorerna är placerade. Detta gör det möjligt att få tätare uppdateringar av t.ex. position och hastighet för det uppkopplade fordonet. På så sätt kan man få information om trafikförhållandena över en längre vägsträcka och samtidigt uppnå större precision för mindre vägsegment med färre antal fasta detektorer. Med hjälp av det uppkopplade fordonet skulle man också kunna informera föraren om tillfälliga hastighetsförändringar, vilket skulle kunna innebära att de variabla hastighetsskyltarna som finns i dag inte längre behövs. Man skulle till och med kunna tänka sig att man inte bara informerar föraren om aktuell hastighet, utan också styr fordonen mot den aktuella hastigheten i likhet med adaptiva farthållare för att få bättre efterlevnad. Detta leder till att variabla hastighetsstyrningssystem skulle kunna tillämpas på vilken motorvägssträcka som helst.

Målet med den här avhandlingen är att öka kunskapen om hur system som bygger på hastighetsstyrning med hjälp av variabla hastigheter, på ett effektivt sätt kan dra nytta av uppkopplade fordon för att förbättra framkomligheten. Avhandlingen föreslår förbättrade och nya metoder som utnyttjar uppkopplade fordon för skattningen av trafikförhållandena, i designen av styralgoritmen och vid tillämpning av de aktuella hastigheterna. Metoderna utvärderas med hjälp av mikroskopisk trafiksimulering, vilket innebär att man beskriver enskilda fordons rörelser i trafikflödet med hjälp av matematiska modeller. Detta är viktigt vid modellering av uppkopplade fordon då information från, och styrning av hastigheten, för enskilda fordon i trafikflödet krävs.

I framtidens trafik med självkörande fordon, allt högre andel fordon uppkopplade till internet och stora krav på framkomlighet, säkerhet och miljö krävs stora anpassningar av dagens trafiksystem. Ett variabelt hastighetsstyrningssystem som utnyttjar möjligheten till information till och från fordon skulle kunna vara en naturlig del i framtidens trafikstyrningssystem. Nyttan med ett sådant system visas tydligt i avhandlingen. 


\section{Acknowledgments}

The research included in this thesis was carried out at the Swedish National Road and Transport Research Institute (VTI) and The division of Communication and Transport Systems (KTS) at Linköping University. The research has been financed by the Swedish Transport Administration through the Center for Traffic Research (CTR) and partly in corporation with the Royal Institute of Technology (KTH).

Writing this thesis is one of the most fun and at the same time the most challenging things I have ever done. It is thanks to a lot of people that I have made it.

First of all, I would like to thank my supervisors Jan Lundgren and Andreas Tapani. I am very grateful for your guidance and support, for letting me go my own way and for being there when needed. I have learned a lot.

I am also grateful to Xiaoliang Ma at KTH for a lucrative collaboration, Bengt Hallström at the Swedish Transport Administration for the engagement in my research and the Swedish ITS Postgraduate School (NFITS) for contributing to a stimulating community within my research area.

Thanks to all my colleagues at KTS and VTI. I have appreciated being part of two inspiring research environments, as well as friendly atmospheres with lots of laughs and interesting discussions. Some of you have contributed to this thesis by reading and discussing my work, it is really appreciated. I am also thankful to the administrative staff for making the administrative work easy. A special thank to Fredrik 
Johansson, it has been a true privilege to share my $\mathrm{PhD}$ time with you both as a friend and as a support to my research and the ups and downs coming with it. Henric Jonsson, you have become a good friend and a source to renewed energy at work. You are truly missed at KTS.

To my family and friends, thank you for always being there, for your endless support and your love. To my beloved Tobbe, I couldn't have done it without you. Thank you for always believing in me. Saga and Emil, I am so thankful for all your love and joy always giving me the strength to keep going.

Norrköping, March 2018 Ellen Grumert 


\section{Contents}

$\begin{array}{ll}\text { Abstract } & \text { iii }\end{array}$

Populärvetenskaplig sammanfattning $\quad \mathrm{V}$

Acknowledgments vii

1 Introduction 1

2 Variable speed limit systems 5

2.1 Effects of variable speed limit systems 6

2.2 Structure of a VSL system $\quad 8$

2.2.1 Control algorithm 9

2.2.2 Traffic state estimation 11

2.2.3 Application of the speed limits 15

3 Connected vehicles 17

3.1 Development of connected vehicles 17

3.2 Connected vehicles as part of a VSL system 19

3.3 Examples of VSL systems using connected vehicles 22

4 Microscopic traffic simulation 25

4.1 Models in microscopic traffic simulation 27

4.2 SUMO 30

4.2.1 Car-following 31

4.2.2 Lane-changing 31 
4.3 Microscopic traffic simulation applied to VSL systems

$5 \quad$ The present thesis $\quad 37$

5.1 Objectives 38

5.2 Research method 39

$5 \cdot 3$ Delimitations 40

5.4 Contributions 41

5.5 Included papers $\quad 42$

5.6 Future research 52

$\begin{array}{ll}\text { Bibliography } & 57\end{array}$

$\begin{array}{lr}\text { Included papers } & 81\end{array}$ 


\section{Chapter 1}

\section{Introduction}

Today, traffic congestion is observed on a daily basis in the larger cities around the world. OECD International transport forum (2017) conclude that the motorised mobility in cities is, assuming the same trends as in the last decades, expected to increase with $100 \%$ between 2015 and 2050. This is creating large costs for the society with negative effects on traffic efficiency, traffic safety and the environment (Lockwood, 2005; Falcocchio and Levinson, 2015).

Automatic traffic management systems, also known as traffic control systems, have high potential to solve problems related to traffic congestion and especially for recurrent congestion where clear patterns exist for when to apply a control strategy. Traffic control systems are used for gathering of information about the traffic conditions and for communication of a specific control strategy. The goal of the traffic control system is to control the traffic in a way that lead to a better traffic situation.

Traditionally, stationary detectors are used to measure the traffic conditions and variable message signs installed on gantries over the road and traffic signals are used to communicate the control strategy. However, recent advancements in vehicle technology have resulted in connected vehicles. Connected vehicles apply wireless communication 
technology to connect the vehicle and devices inside the vehicle itself with surrounding vehicle devices and the infrastructure. The connected vehicles can act as detectors by continuously communicating information about their speed, position, distance to the vehicle in front, etc. Thereby, the traffic conditions can be estimated at arbitrary locations. Further, connected vehicles have the possibility to retrieve information about the control strategy. Hence, it is possible to make use of connected vehicles in traffic control systems to allow for control at arbitrary positions. By doing so the amount of expensive infrastructure equipment, such as stationary detectors and variable message signs, can be reduced.

The choice of traffic control system is dependent on the traffic situation. For urban areas the goal is often to reduce the traffic flows in order to increase safety, reduce speeds and to get a more liveable city. It might also be the case that the goal is to reduce the road capacity in order to get a transition from private passenger cars to other travel modes. Examples of capacity and traffic flow reducing systems commonly applied in urban areas are traffic signals (Gartner, 1983; Mirchandani and Head, 2001; Srinivasan et al., 2006; He et al., 2014), re-routing (Pan et al., 2012; Wang et al., 2014) and tolls (Börjesson and Kristoffersson, 2015; Ekström et al., 2016). In rural areas and on motorways, the roads are usually important for connecting the suburbs with the city centre or for longer transitions between important areas. Therefore, systems with the aim of increasing efficiency and safety are commonly applied. The two most common examples are Variable Speed Limit (VSL) systems (van den Hoogen and Smulders, 1994; Hegyi et al., 2005; Abdel-Aty et al., 2006; Lee et al., 2006; Maunsell and Parkman, 2007; Carlson et al., 2011) and ramp metering (Papageorgiou et al., 1991; Gomes and Horowitz, 2006; Meng and Khoo, 2010; Geroliminis et al., 2011; Bhouri et al., 2013).

Urban motorways do often experience daily congestion during peak-hours. The cause of the congestion might be twofold; either the congestion is created at stationary bottlenecks as a result of demand exceeding capacity or as a result of large or small disturbances, so 
called incidents. An incident is an unplanned event that lead to a reduction of traffic capacity and traffic safety. This can for example be an accident, adverse weather conditions, slow moving vehicles or obstacles on the road (Taylor et al., 2015). The incidents are creating so called non-recurrent bottlenecks.

Ramp metering is aiming at improving the traffic conditions on the main road by limiting the incoming traffic flows from minor roads by the use of traffic signals. In this case, the congestion at an on-ramp is observed frequently, and usually during peak-hours, resulting in a recurrent bottleneck. The main goal of a VSL system is to adapt the speed limit to prevailing traffic conditions. Hence, VSL systems can handle both recurrent and non-recurrent bottlenecks. The amount with which the speed limit is reduced is depending on the traffic situation to be solved. If the goal is to increase safety the speed limits are usually substantially reduced with a fixed amount, whereas if the goal is to increase efficiency the speed limits are lowered in proportion to the capacity, i.e. the maximum throughput of vehicles, at the bottleneck.

A VSL system consists of three parts; the control algorithm used for deciding on which speed limit to be displayed, an estimate of the traffic conditions to be used as input in the control algorithm and the infrastructure for application of the speed limits. The control algorithm is used to calculate appropriate speed limits based on the prevailing traffic conditions. The algorithm can be coordinated, considering multiple road segments when deciding on the speed limit to be used, or isolated, only considering one road segment. In existing VSL systems, the traffic conditions used as input to the control algorithm are commonly measured by the use of stationary detectors and the infrastructure for application of the speed limits are consisting of coordinated variable message signs installed on gantries over the road. The speed limits can be both recommended or compulsory.

This thesis examine how connected vehicles can be used to increase the benefits of VSL systems. The focus is to increase traffic efficiency. The six papers included in the thesis contribute with knowledge about the usefulness of existing VSL systems and the inclusion of connected 
vehicles in existing VSL systems, as well as suggestions on how connected vehicles can be used to improve traffic efficiency by applying new and improved methods for all three parts of a VSL system. The methods are evaluated by microscopic traffic simulation. The overall conclusion is that the use of connected vehicles in VSL systems can contribute to improvements in traffic efficiency compared to existing systems.

The remainder of this thesis is organized as follows. Chapter 2 gives an introduction to VSL systems. This is followed by an overview of connected vehicles and its possible use in VSL systems. Chapter 4 presents the evaluation method and discuss how microscopic traffic simulation can be used for evaluation of VSL systems. In Chapter 5 the objectives, research method, delimitations and contributions of this thesis are specified, together with a summary of the included papers. Finally, six papers are included. 


\section{Chapter 2}

\section{Variable speed limit systems}

Variable Speed Limits (VSLs) are one of the most commonly applied traffic control systems on motorways. Single VSLs are used to display speed limits that are adjusted with a fixed amount based on the prevailing traffic conditions. The speed limit is communicated to drivers on variable message signs. The aim of the change in speed limit is to increase safety and efficiency for a limited part of a road stretch. Lower speed limits can for example be displayed during incidents, road works, bad weather, etc.

However, on urban motorways, traffic congestion appear at peakhours and propagate over a longer road stretch. One single VSL, lowered with a fixed amount, is therefore not enough to give a desirable effect on urban motorways when the aim is to improve the traffic conditions as a result of congestion and incidents. This has resulted in VSLs that are linked together via a control algorithm, so called VSL systems. In this thesis, the focus is on VSLs with the aim to improve the traffic conditions on urban motorways. Hence, from here on VSL systems are being further discussed. First, effects of variable speed limit systems are presented. This is followed by a description of the important parts of a 
VSL system.

\subsection{Effects of variable speed limit systems}

VSL systems were first introduced in the 1960's (Lu and Shladover, 2014) and as a motorway traffic control in the 1970's (Soriguera et al., 2017). The benefits of the VSL system varies depending on the aim. Two main approaches exists (Khondaker and Kattan, 2015b; Lu and Shladover, 2014; Soriguera et al., 2017), although somewhat differently defined in the different studies. In this thesis the two main approaches are defined as: (1) increasing safety by reducing the speed limit substantially when an incident has occurred, and thereby decrease the probability of further collisions (incident detection systems), (2) prevent a traffic breakdown by applying a speed limit corresponding to a traffic flow close to capacity without entering unstable traffic conditions (homogenization systems). VSL systems have been applied in real traffic and evaluated through simulation studies. Lu and Shladover (2014) and Khondaker and Kattan (2015b) gives an overview of different VSL strategies developed over the last decades.

The incident detection systems, sometimes also referred to as warning systems, have as main objective to detect situations where incidents have happened. This means that the system is triggered when a breakdown, i.e. very low speeds are detected. The purpose with the change in speed limits is to limit the risk of further breakdown and to resolve the congestion caused by the incident.

The main objective of the homogenization systems is to prevent a breakdown. It is well-known that the capacity at the onset of congestion tend to drop. The drop has been discovered in many empirical studies, see e.g. Srivastava and Geroliminis (2013), Chung et al. (2007) and Zhang and Levinson (2004). According to Zhang and Levinson (2004) and Daganzo and Laval (2006), the capacity drop can partly be explained by the increased number of lane-changes during unstable traffic conditions. Another consequence from frequent lane-changes is speed oscillations as shown by Ahn and Cassidy (2007) and Duret et 
al. (2009). The homogenization systems aims at reducing differences in speed amongst the drivers, and thereby also reduce the number of performed lane-changes and speed oscillations. By doing this a capacity drop, resulting in a breakdown, can be delayed or even avoided. Hence, it is not necessarily when the mean speed on the road becomes low that the systems are triggered. Soriguera et al. (2017) conclude that empirical studies, as early as 1972 , indicate that homogenization can be obtained when the speed limit is around critical levels, i.e. close to capacity. Many of the studies, including the one by Soriguera et al. (2017), show that a higher critical density, i.e. the density at which the maximal throughput of vehicles occur, can be obtained without notably reducing the traffic flow when lower speed limits are applied.

Examples of implemented VSL systems are the systems in the UK (Maunsell and Parkman, 2007), the Netherlands (van den Hoogen and Smulders, 1994) and Sweden (van Toorenburg and de Kok, 1999). The systems are incident detection systems, with thresholds of speed and flow for deciding on the speed limits to be applied. Studies from existing systems show benefits in traffic safety and homogenization (reduction of variance in speed), while improvements in traffic efficiency are limited. For the M25 controlled highway in the UK (Maunsell and Parkman, 2007) benefits are observed with respect to flow homogenization, emission levels, and safety. Similarly, a comparative study by Smulders and Helleman (1998) between the systems in the Netherlands, the UK and Germany, indicate benefits in terms of increased homogenization and safety effects. Both the study performed in the UK and the comparative study show limited improvements in throughput, capacity and congestion. Also, a study of the Swedish system (Nissan and Bang, 2006; Nissan and Koutsopoulos, 2011) show improvements in terms of homogenization, although the results are not statistically significant. The limited improvements can according to the authors possibly be explained by the fact that the displayed speed limits are only recommended, and not compulsory. An experiment performed by van den Hoogen and Smulders (1994) indicate that the integration of a homogenization algorithm have positive effects on the speed distribution between lanes, 
leading to a more stable traffic flow.

The limited improvements in traffic efficiency can also be a result of the simplistic rules and the big difference between the displayed speed limit and the original speed limit on the road. This means that the traffic conditions on the road are likely to already be in a congested state when the variable speed limits are activated. Hence, the variable speed limit is not reflecting the actual flow on the road, and becomes more of an indicator or a warning to the drivers of congestion/incidents further downstream.

\subsection{Structure of a VSL system}

The VSL systems can be decomposed into three important parts: a control algorithm for deciding on appropriate speed limit, a method for estimating the traffic state used as input to the control algorithm and the infrastructure for application of speed limits. The traffic state refer to the current traffic conditions on a road segment and are commonly composed by macroscopic variables, such as mean speed, flow and density. Additionally, traffic flow parameters can be part of the traffic state. The traffic flow parameters describe the characteristics of the traffic for the given location. Examples are the capacity at which the maximum throughput of vehicles are observed and the desired speed of the vehicles for the given road. Figure 2.1 gives an overview of the three parts and how they relate to each other.

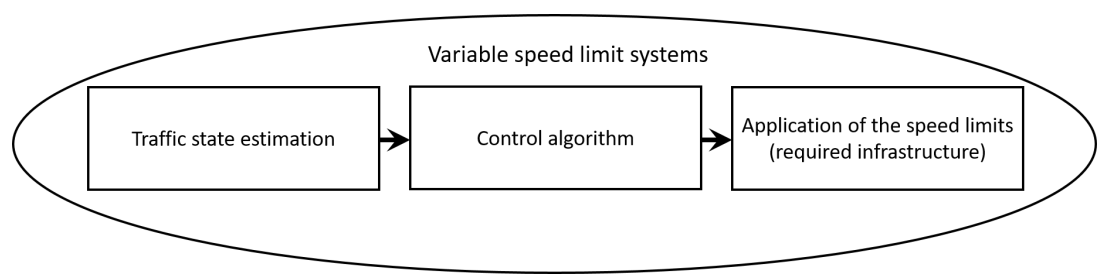

Figure 2.1: Overview of the three parts included in a variable speed limit system.

The control algorithm is the foundation of a VSL system. The design 
of the algorithm is based on the goal of the VSL system which can be one or more of improving safety, efficiency or reducing environmental impacts. It can be isolated, only considering one road segment, or coordinated, considering many road segments when deciding on the speed limit to be applied. The traffic state estimation is used to get a picture of the prevailing traffic conditions, which is an input to the control algorithm together with a set of algorithm specific parameters. Today, the traffic conditions in implemented VSL systems are estimated using measurements collected through stationary detectors, where the most common measurements to use are local speed or flow. The speed limit, given as output from the VSL algorithm, is applied on predefined road segments. The infrastructure at which the speed limits are applied can differ. However, in implemented systems the speed limits are displayed on variable message signs. The displayed speed limits are either compulsory or recommended.

\subsubsection{Control algorithm}

The design of the control algorithm is reflected in the purpose of the VSL system and the required level of detail in the implementation and this will in turn have an affect on the resulting outcome. The objective might sometimes even be contradictory. For example if safety is the main objective, the algorithm is more probable to assign low speed limits, resulting in longer travel times and maybe also higher pollutant emissions. If efficiency is the main objective, safety might decrease. And finally, if emission levels is the main objective, the algorithm might assign lower speed limits due the fact that vehicles often performs at their best, with respect to emission levels, at around $70 \mathrm{~km} / \mathrm{h}$ (Den Tonkelaar, 1991). But on the other hand, many studies have concluded that homogenization lead to better traffic situations, see e.g. Maunsell and Parkman (2007), Smulders and Helleman (1998), Lee et al. (2006), Carlson et al. (2011), and Li et al. (2014b), and this will most probably affect both travel times, emission levels, and safety in a positive manner.

VSL algorithms can be categorized into four different types: rule 
based, fuzzy-logic based, analytical and control-theory based. The simplest VSL systems include rule-based VSL control algorithms. The algorithms use thresholds for identifying incidents and situations with low speeds. Most of the VSL systems used in practice are rule-based. Examples of implemented rule-based VSL control algorithms are included in the UK (Maunsell and Parkman, 2007), the Swedish (van Toorenburg and de Kok, 1999) and the Dutch (van den Hoogen and Smulders, 1994) Motorway Control Systems (MCS) and the Spanish dynamic speed limit system (Soriguera et al., 2013). Examples in the literature are given by Lee et al. (2006), Allaby et al. (2007) and Li et al. (2014a).

Another type of VSL control algorithm is the fuzzy-logic based control algorithm, where the speed limits are decided based on how well the measured input matches a set of rules, see e.g. Li and Ranjitkar (2015), Liang and Wang (2012) and Chiou et al. (2012). The rules can for example be "if downstream flow is low then the speed limit is high" or "if downstream occupancy is high then the speed limit is low". The measured output becomes members of a specific speed limit to some degree. The membership is based on a membership function derived from data. The final speed limit to apply on a road stretch is the one with the highest degree of membership.

In analytical VSL control algorithms the purpose is to analytically calculate the traffic states based on a measured reality, see e.g. Hegyi et al. (2008) and Han et al. (2017b). This result in an application area for where to apply the speed limits, as well as the time for the speed limit reduction to be active. Usually the speed limits are lowered with a fixed amount, which is used as input when calculating the application area and the duration of the reduction.

Finally, control theory based VSL control algorithms have been proposed to find the optimal VSL strategy based on local feedback loops, such as the algorithms proposed by Carlson et al. (2011) and Jin and Jin (2015) or by using model predictive control, see e.g. Hegyi et al. (2005), Zegeye et al. (2009), Frejo et al. (2014) and Han et al. (2017a). A common local feed back controller is a PID controller (proportionalintegral-derivative controller), which is a three-term controller, trying 
to control the error between a measured value and a predefined target value. One or more of the terms can be included in the control algorithm and the speed limit is lowered or increased based on the size of the error. The proportional term of the controller $(\mathrm{P})$ controls the current output of the algorithm towards the set point. The integral term of the controller (I) will control the effects of the historical cumulative value of the error. The derivative term of the controller (D) is related to the prediction of the future errors based on the current rate of change. In model predictive control (Morari and Lee, 1999; García et al., 1989) the future traffic states are predicted based on a dynamic model of the process, i.e. the traffic flow evolution, a history of past control actions and an optimization cost function. The optimization process, with the aim of minimizing the cost function, results in a final speed limit to be displayed on the VSL signs. The design of the cost function is dependent on the aim and the purpose of the VSL system. Examples of algorithms based on model predictive control presented in the literature are Hegyi et al. (2005) and Zegeye et al. (2011).

According to Hegyi et al. (2008), many of the algorithms proposed in the literature often require a considerable amount of data, are computationally complex, have uncertainty in robustness and/or tuning difficulties of parameters. The tuning difficulties are the result of too many parameters to tune or interpretation issues of the parameters. Hence, for real world applications it is desirable to limit the complexity of the control algorithm, but of course without loosing too much of the advantages that comes with the more advanced control algorithms.

\subsubsection{Traffic state estimation}

Density, flow and speed are three fundamental traffic variables with which the dynamics of traffic can be described. These variables are, for a given road stretch, usually referred to as the traffic state. An estimate of the traffic state is an important input for finding a suitable VSL control strategy. A wide variety of methods, as well as data sources, to base the traffic state estimation on exists in the literature. In this thesis the focus is on traffic state estimation applicable to VSL control strategies. For a 
more thorough overview of methods for estimating the traffic state, see Seo et al. (2017).

The traffic state estimation used in VSL systems is based on measurements of the traffic system. The most exact method when estimating the traffic state is to use aerial photographs taken by for example a helicopter, video cameras or images, given that the images have a high resolution. Already in the early 1900's research using photographs was presented by Greenshields (1934). Later studies make use of video cameras for estimation of densities. See for example Knoop et al. (2008), Ossen and Hoogendoorn (2011) and Asmaa et al. (2013). However, according to Darwish and Bakar (2015), the costs related to the methods are usually large or the methods becomes impractical due to inaccurate and time consuming image processing.

Instead, the most common way to estimate the traffic state is to make use of information collected from stationary detectors, such as loop detectors, radar detectors, etc. (Coifman, 2003). This is limiting the estimation to specific points in space, and the conditions in between detectors remains unknown. Data assimilation and fusion techniques are often used to get the picture of the traffic state also in between the detectors. These methods are usually based on an underlying model of the traffic evolution and a filtering approach to take into account various data sources. A number of studies using different underlying models and different filtering approaches exists in the literature, see e.g. Kurkjian et al. (1980), Muñoz et al. (2003), Wang and Papageorgiou (2005), Mihaylova et al. (2007), Singh and Li (2012) and Duret et al. (2016). An overview of Kalman filtering in traffic applications and more examples from the literature can be found in van Lint and Djukic (2014). Darwish and Bakar (2015) concludes that methods using different types of stationary detectors can estimate the traffic state accurately but they are often expensive to install and maintain, and limited to small areas. Also, the information is usually transmitted with delay since they have to be processed through a traffic information center.

Additionally to the traffic state estimation, traffic flow parameters can be used as input to the control algorithm to describe parameters 
and target values. The traffic flow parameters describe the characteristics of the traffic state for a given road stretch. Examples of traffic flow parameters are the density observed at the maximum throughput of vehicles (critical density), the uninterrupted speed at low flow levels (free flow speed), the maximum density in standstill traffic (jam density), the maximum throughput of vehicles (capacity) and the time gap to the vehicle in front in stand still traffic (time gap). The traffic flow parameters are affected by the the road infrastructure such as the geometry of the road, the maximum allowed speed limit, etc. But it is also affected by the vehicle composition, such as the distribution of vehicle length, the acceleration and deceleration abilities, the allowed speed for different vehicle types, etc. and the environmental conditions such as weather conditions, incidents and so on. The traffic flow parameters used as inputs to the control algorithm have to be defined or estimated based on prior and current knowledge about the traffic system.

One common approach to estimate the traffic flow parameters is by the so called fundamental diagram. The fundamental diagram is a mathematical description of the fundamental relations between speed, flow and density at specific road stretches. The parameters included in the mathematical description of the fundamental diagram are often describing the traffic system, i.e. they are representing some of the traffic flow parameters of the traffic system. Many mathematical relations of the fundamental diagram have been proposed during the years (Wang et al., 2010), with the earliest ones as early as 1934 (Greenshields, 1934). The models are of different degree of complexity with the simplest ones being single-regime models. The single-regime models includes one expression for describing all the states, i.e. free-flow, congested, synchronized etc. (Drake et al., 1967; Pipes, 1967; Kerner and Konhäuser, 1994; van Aerde and Rakha, 1995). Two- (Edie, 1961; Wu, 2002) and threeMay (1990) regime models have been proposed to resolve the difficulties with matching both the congested and the uncongested part of the fundamental digram with data in the single-regime models. The main problems of the two- and three-regime models is to find the breakpoints between the states. Lately, the fundamental diagram has also been rep- 
resented based on a stochastic approach (Wang et al., 2013; Jabari and Liu, 2013; Qu et al., 2017)

The fundamental diagram and its parameters are commonly found by performing off-line calibration, meaning that the calibration is performed using empirical data of the traffic state from the past. Optimization and regression techniques are used to find the best fit of the fundamental diagram to the empirical data (van Aerde and Rakha, 1995; Dervisoglu et al., 2009; Qu et al., 2015, 2017; Zhong et al., 2016; Knoop and Daamen, 2017). This require a predefined functional form of the fundamental diagram. The empirical observations used for calibration of the fundamental diagram are often based on measurements gathered from stationary detectors, such as loop detectors, radars, etc.

However, the traffic state and thereby also the parameters of the fundamental diagram are known to vary due to for example adverse weather conditions, incidents, etc. (Ibrahim and Hall, 1994; Wang et al., 2009). To cover the changes in the traffic state, methods using real-time calibration of the parameters in the fundamental diagram can be applied. These methods are usually combined with a macroscopic traffic model and a filtering approach. In this case, the parameters are becoming part of the traffic state and can thereby be modelled as a random process which are allowed to change over time. Wang and Papageorgiou (2005) and Wang et al. (2009) use an extended Kalman filter and a second-order traffic model to estimate the parameters in real-time. The goal is to improve the accuracy of the traffic model and to examine if the changes in parameters can be used to identify non-normal traffic situations such as incidents. Also Tampère and Immers (2007) use an extended Kalman filter, but show that it is enough to apply a first-order model to describe the evolution of traffic and for real-time estimation of the parameters. The parameters manage to adapt to variations in the traffic conditions. Another example by Dabiri and Kulcsár (2015) use a bi-parameter approach, where one parameter related to changes in the free flow speed and one parameter related to changes in the headway are incorporated to a macroscopic traffic flow model. The approaches are commonly used for incident detection in order to detect 
abrupt changes in the traffic state, which is useful for finding a good traffic management strategy. Other methods use real-time calibration of the traffic flow parameters to find target values in dynamic motorway traffic control strategies at fixed locations. An example is given by Ozbay et al. (2006), where the critical density and the density is representing the traffic state and an extended Kalman filter is applied to find time dependent estimates of the critical occupancy, which is related to the critical density. The critical occupancy is used as a target value to the local ramp metering strategy ALINEA (Papageorgiou et al., 1991).

The traffic flow parameters used as input to a control algorithm have also been estimated in real-time without the use of a fundamental diagram. In Smaragdis et al. (2004), the critical occupancy is estimated by letting it change over time based on the rate of change of flow with respect to the change in occupancy. The critical occupancy is a target value in the local ramp metering strategy ALINEA (Papageorgiou et al., 1991). A similar method has been applied in perimeter control, with the goal to control the inflow to a larger urban area by applying traffic signals (Ampountolas and Kouvelas, 2015).

\subsubsection{Application of the speed limits}

Infrastructure is needed for communication of the variable speed limits. Today, the infrastructure of VSL systems consists of variable message signs installed on gantries over the road (Maunsell and Parkman, 2007; Nissan and Koutsopoulos, 2011). This means that a driver has to observe the changes in speed limits at discrete points in space. As a result, it will take some time until the traffic system adapt to changes in the speed limits due to the inability to get information about changes in between two variable message signs. Additionally, the speed limits are only changed at discrete points in time and usually with some limitations on how often a change can occur to avoid fluctuations in speed limits. This will slow down the adaptation towards the current traffic situation, due to a delay in displaying the speed limits.

The speed limits can be both compulsory (Maunsell and Parkman, 2007; van den Hoogen and Smulders, 1994) and recommended (Nissan 
and Koutsopoulos, 2011). If the speed limits are compulsory they are usually installed together with a speed camera to increase the compliance. It has been concluded by for example Nissan and Koutsopoulos (2011) and Berg and Bukkems (2001), that if the speed limits are only recommend the compliance level is lower, resulting in limited effects of the VSL system, especially on traffic efficiency. It can even be the case that the deviations in speed is increased due to some compliance, whilst others ignore the recommendations. Larger improvements are seen with systems using compulsory speed limits and speed cameras (Maunsell and Parkman, 2007; van den Hoogen and Smulders, 1994).

Further, it is known that different drivers have different desired speed. So even though the speed limits from a VSL system are displayed on variable message signs there will be deviations in speed similar to what is observed without the system. However, a reduction in speed deviations is observed for many of the implemented systems (Maunsell and Parkman, 2007; van den Hoogen and Smulders, 1994; Nissan and Koutsopoulos, 2011). This is probably a combination of the lower speed limits and the fact that the allowed speed differ for different vehicle classes (trucks, passenger cars, etc.). The effect of different allowed speed limits does mainly affect motorways with a high original speed limit, above $80 \mathrm{~km} / \mathrm{h}$, since some vehicle classes are not allowed to drive faster than this. So, by introducing lower speed limits during congestion the deviations will decrease since all vehicles are able to drive according to the speed limits and not at a lower speed due to restrictions of specific vehicle classes. 


\section{Chapter 3}

\section{Connected vehicles}

The rapid development in vehicle communication technology has resulted in connected vehicles. Connected vehicles make use of communication between vehicles and vehicles and the infrastructure to continuously send and receive information about the current traffic conditions. The information can be used to inform and warn the driver about upcoming situations on the road or for control of the vehicle by application of a traffic control system.

This section gives an introduction to connected vehicles and how connected vehicles can be used in the three parts of a VSL system. Examples of existing studies on VSL systems using connected vehicles are presented.

\subsection{Development of connected vehicles}

Both traffic operators and vehicle manufacturers have had a strong interest in the development of information and communication technologies over the years, so called Intelligent Transport Systems (ITS) (European Commission, 2009), and systems and technologies supporting ITS have been developed and deployed all over the world. One of the first research project within the area of ITS was 
PROMETHEUS (Diebold, 1995). The project started in 1986 with several project partners from the vehicle industry. The focus within the project was on the vehicle side. Many of the ideas within the project was related to something which were later defined as cooperative systems. The idea behind cooperative systems, compared to the more 'traditional' ITS, according to the European Commission (2009), is to increase the amount of real-time information given to the driver by two-way communication between vehicles (Vehicle-to-Vehicle $\left(\mathrm{V}_{2} \mathrm{~V}\right)$ ), and between vehicles and the infrastructure (Infrastructure-to-Vehicle $(\mathrm{I} 2 \mathrm{~V})$, Vehicle-to-Infrastructure ( $\mathrm{I} 2 \mathrm{~V})$ ). The additional information flow can contribute to improvements for the individual vehicles as well as for the whole traffic system. The problem at the time of PROMETHEUS was the limited technology available, and many of the ideas within the project remained as just ideas. Since PROMETHEUS in the 1980's, the communication technologies has had a tremendous development, resulting in the introduction of cooperative systems in many research projects worldwide. In Europe the framework programs (European Commission, 2010) is a big contributor to the research of cooperative systems, see e.g. CVIS (CVIS, 2010), SAFESPOT (Safespot, 2010), COOPERS (COOPERS, 2010a,b) and PreDrive $\mathrm{C}_{2} \mathrm{X}$ (Schulze et al., 2010; Enkelmann et al., 2008). In U.S, the Department of Transportation, U.S. DOT, early supported and promoted the development of cooperative systems with projects like VII/Intelli- Drive (The VII Consortium, 2009; U.S. DOT, 2009), VSC (Laberteaux, 2006; Shulman and Deering, 2004; Shulman, 2009) and EEBL (Shulman, 2009). Japan started the research on cooperative systems with support from the government already in 1989. Examples of some of the larger projects are AHSS(Gee, 1997), ASHRA (Gee, 1997; Schulze, 2006), Smartway (Schulze, 2006), ASV (IATSS Research, 2006; Wani, 2006; Gee, 1997) and VICS (VICS, 2010). With the introduction of cooperative systems, the vehicle industry has taken another step in the direction towards fully autonomous, or self-driven vehicles. Today, the idea of having an autonomous vehicle driving on the roads in a near future has become a main target within many projects all over the world. 
Connected vehicles are strongly correlated to and sometimes a necessity for cooperative systems. The connected vehicles (Coppola and Morisio, 2016) make use of internet to connect the vehicle and devices inside the vehicle itself with surrounding vehicle devices and the infrastructure, i.e. $\mathrm{V}_{2} \mathrm{~V}-$, $\mathrm{V} 2 \mathrm{I}-$ and $\mathrm{I} 2 \mathrm{~V}$-communication. In-vehicle systems and traffic control systems making use of connected vehicles can be seen as standalone cooperative systems, but also as sub-systems in autonomous vehicles. Hence, it becomes important to identify promising in-vehicle and traffic control systems using connected vehicles and understand the resulting effects of such systems in order to accelerate the development of connected vehicles and systems using $\mathrm{V}_{2} \mathrm{~V}-$, V2I- and I2 $\mathrm{V}$-communication.

\subsection{Connected vehicles as part of a VSL system}

The three parts included in a VSL system, see Figure 2.1, can make use of connected vehicles and thereby possibly improve the performance of the VSL system. This can be achieved by introducing new methods using connected vehicles or extending existing methods to include connected vehicles. The design of the control algorithm itself is often independent of the use of connected vehicles. Hence, the main parts where connected vehicles can be useful are in the traffic state estimation and in the application of speed limits.

In the traffic state estimation and for finding the traffic flow parameters, the connected vehicles can be used as an additional source of information about the traffic conditions on the road. The type of information that is available is speed of the vehicles, location, distance to vehicle in front, etc. The connected vehicles can be used in combination with stationary detectors or as a standalone source of information. The main benefit of using connected vehicles for traffic state estimation is the possibility to get information at arbitrary locations, which is not possible with the stationary detectors. Further, the use of sta- 
tionary detectors can be reduced, which in turn will reduce the cost related to installation and maintenance of the stationary detectors. A number of studies have been proposed in the literature that are making use of connected vehicle data as an input to the commonly applied filter approaches in order to update the modelled traffic state. Herrera and Bayen (2008) use a Kalman filtering approach to incorporated mobile phone data to the underlying macroscopic traffic model. Work et al. (2010) use an ensamble Kalman filter together with data from GPS enable mobile devices. In Yuan et al. (2014), an extended Kalman filter is used for data assimilation, and lagrangian coordinates, i.e. vehicle spacings and speed, is used as input data to the filter. In Seo et al. (2015b), measurements of gaps to the vehicles in front of connected vehicles are used together with an ensemble Kalman filter to estimate the traffic density. Astarita et al. (2006) and Bekiaris-Liberis et al. (2016) develop macroscopic cell transmission type models for the dynamics of the percentage of connected vehicles along the considered road. In Astarita et al. (2006), the density is estimated based on percentage of connected vehicles. The dynamics of the percentage of connected vehicles is modelled with a macroscopic cell transmission model. It is assumed that the connected vehicles move with the same average speed as the nonconnected vehicles, and hence no modelling of the speed dynamics is needed. Similarly, Bekiaris-Liberis et al. (2016) uses the penetration rate of connected vehicles together with measurements of speed from the connected vehicles to estimate the density.

Other methods are making use of connected vehicle data without an underlying traffic model. Herring et al. (2010) uses travel time data from taxis together with a particle filter in order to estimate the traffic state. Herrera et al. (2010) make use of the speed of the connected vehicles to get an estimate of the speed of the traffic state. van Lint and Hoogendoorn (2010) apply the extended generalized Treiber-Helbing filter to fuse multiple data sources. Qiu et al. (2010) and Ma et al. (2011) uses connected vehicles and detectors to estimate the traffic density on a road stretch. Bhaskar et al. (2014) uses count of vehicles from inductive loops together with travel time received from Bluetooth MAC 
Scanners to estimate density at different segments. Zhang et al. (2015) uses connected data and detectors in order to estimate the space-mean speed on a road stretch. In Seo et al. (2015a) and Montero et al. (2016), measurements of gaps to the vehicle in front of the connected vehicle are used to estimate the traffic density. Seo and Kusakabe (2015) uses the time-space interval between two connected vehicles and the conservation of vehicles is used to estimate the density.

Methods using connected vehicles have also been applied for calibration of the fundamental diagram. For example, Seo et al. (2017) calibrate the fundamental diagram based on trajectories from connected vehicles. Clairais et al. (2016) used loop detectors and connected vehicle data to minimize the difference between the observed travel times and the calculated travel times based on the fundamental diagram. Both of these methods are applying off-line calibration.

The speed limits in implemented VSL systems are displayed on variable message signs. However, by the introduction of connected vehicles the speed limits can be communicated directly to the vehicle and the required infrastructure for communication of the speed limits can be reduced. The speed limits can be given as recommendations to the driver, which require that the driver takes an active decision to change speed, or by applying direct control similar to an adaptive cruise control. In order for VSL systems using control of connected vehicles to have an effect, the penetration rate of connected vehicles i.e. how many vehicles that are equipped with the systems, is important. But even more important is to have a high user acceptance and a high level of compliance, meaning the number of users that accepts and understand the functionality of the system, and have a the desire to change speed or turn on an adaptive cruise control to obey with the given speed limits. This is especially important for systems that are aiming at improving the overall performance of the traffic system, which is the case for VSL systems. 


\subsection{Examples of VSL systems using connected vehicles}

Recent studies have investigated how connected vehicles can be used as part of a VSL system. Yang and Jin (2014) use connected vehicles to calculate a speed limit with the objective to smooth the vehicle trajectories in stop and go traffic. The authors show that by making use of connected vehicles, the environmental impacts can be reduced without decreasing traffic efficiency. Kattan et al. (2015) extend a VSL algorithm based on model predictive control (Hegyi et al., 2005). The aim is to minimize travel time by including speed measurements from connected vehicles. It is concluded that traffic efficiency can be improved but the impact is dependent on the traffic conditions. The authors even show that the VSL algorithm result in a decreased traffic efficiency for some cases. Further, the use of connected vehicles as detectors is not always the best alternative compared to stationary detectors, especially if the update frequency is low. Khondaker and Kattan (2015a) take into account estimates of each connected vehicle's total travel time, time to collision and emission levels to optimize the aggregated values based on model predictive control. The goal is to find the optimal speed limits to be displayed on VSL signs. Only insignificant improvements were shown. Wang et al. (2016) introduce a car-following control algorithm based on the surrounding environment of the connected vehicles. Here, the desired speed of the in-vehicle control is based on the VSL algorithm SPECIALIST by Hegyi et al. (2008). The improvements are according to the authors mainly due to a better compliance of the VSL for the connected vehicles, which result in a reduction in the capacity drop. Müller et al. (2016) use connected vehicles to apply speed limits based on the control algorithm proposed by Müller et al. (2015) and Carlson et al. (2011). By doing so the compliance level is increased and the performance of the algorithm is significantly improved. Han et al. (2017b) use connected vehicles to control the inflow at a recurrent onelane bottleneck such that a maximum throughput is guaranteed and a capacity drop is avoided. Some of the important key aspects that, ac- 
cording to the authors, have to be further considered are the method for detection of an active bottleneck and estimation of the parameters of the applied model. This shows on the need to apply an accurate estimate of the traffic state and the important traffic flow parameters, such as the capacity.

As a conclusion, connected vehicles have been shown to be useful both for collecting measurements to estimate the traffic state, which is used as input to the VSL system (Yang and Jin, 2014; Kattan et al., 2015; Khondaker and Kattan, 2015a), and for control of single vehicles as part of the control strategy in the VSL system (Wang et al., 2016; Müller et al., 2016; Han et al., 2017b). 



\section{Chapter 4}

\section{Microscopic traffic simulation}

Traffic simulation is commonly used to investigate the impacts of changes in the infrastructure and implementation of traffic control systems. A traffic simulator consist of mathematical models, describing dynamics of the traffic flow and the movements of individual vehicles within the traffic flow to mimic real traffic. The simulators can be divided into three categories based on the level of detail: macroscopic-, mesoscopic- and microscopic traffic simulation.

Macroscopic traffic simulators describe the traffic flow similar to the movements of liquids or gases (Treiber and Kesting, 2013). The models describe the evolution of aggregated quantities of speed, flow and density in time and space and are commonly composed of partial differential equations, see e.g. Lighthill and Whitham (1955) and Messner and Papageorgiou (1990). This means that local variations and interactions between individual vehicles are not modelled.

Microscopic traffic simulators, describe the interactions between vehicles by models of the longitudinal and latitudinal movements of each vehicle. Each vehicle has its own characteristics represented by its position, speed, acceleration, etc., allowing for detailed simulation 
output such as the resulting distribution of accelerations, speeds and travel times and specific routes of individual vehicles. But also more aggregated outputs are available since each simulated vehicle is contributing to the total traffic stream from where flow, density and speed can be computed. Examples of frequently used microscopic traffic simulators are VISSIM (Fellendorf and Vortisch, 2010), Aimsun (Casas et al., 2010) and Paramics (Sykes, 2010).

A mesoscopic traffic simulator model interactions of the individual vehicles but with a lower level of detail by treating the vehicle dynamics on a macroscopic level (Barceló, 2010). The vehicles can either be modelled as moving packages or platoons, or by modelling the flow dynamics by simplified dynamics of individual vehicles. This allows for simulation of larger networks compared to a microscopic traffic simulator, but with more details included compared to a macroscopic traffic simulator. Examples of mesoscopic traffic simulators are CONTRAM (Leonard et al., 1989), DYNASMART (Jayakrishnan et al., 1994) and MEZZO (Burghout, 2004).

The choice of traffic simulator is a trade-off between the size of the network, the available computational time, the level of detail required in the vehicle dynamics and driver behaviour, as well as the required aggregation level of the simulated output.

The introduction of connected vehicles has increased the need for detailed traffic simulation models. The possibility to continuously send and receive vehicle specific data and to control connected vehicles require modelling of individual vehicles in the traffic flow. Hence, a microscopic traffic simulation model is often necessary.

This chapter gives an introduction to microscopic traffic simulation and describe how it can be used for evaluation of VSL systems. The microscopic traffic simulation tool Simulation of Urban MObility SUMO is used in this thesis, why it is given special attention in the chapter. 


\subsection{Models in microscopic traffic simulation}

Microscopic traffic simulation tools are widely used and some of the most well-known tools are presented by Barceló (2010). A microscopic traffic simulator consists of two core models, the car-following model and the lane-changing model.

The car-following model describes how a single vehicle in the simulation interact with vehicles in front of it. Brackstone and McDonald (1999) gives an comprehensive overview of the development of carfollowing models over the years. One of the first car-following model, the GHR-model is originating from the 1950's as part of General Motors research. The model has been extended and modified since the first version, with many different contributors over the years. The GHR-model is a so called stimulus-response model, where the acceleration of a vehicle (response) depends on some stimulus. The GHR-models are today used less frequently due to the many contradictory findings regarding the model parameters. Another type of model is the safe distance model, or collision avoidance model, where the driver is assumed to maintain a safe distance to the vehicle in front, and thereby avoid collisions. The model proposed by Gipps (1981) is one of the most famous versions of a safe distance model. The main advantage with this model is the realism of the model as a result of the directly measurable model parameters. Other assumptions may be questionable, for example the driver is assumed to only consider one leader and does not look further ahead, when adapting to its safe distance. Psycho-physical, or action point models, uses thresholds of relative speed and relative position for which drivers are assumed to change their behaviour. The most widely used psycho-physical models are presented by Wiedemann and Reiter (1992) and Fritzsche (1994). The psycho-physical models are expected to represent the everyday driving behaviour best. However, the calibration of the thresholds and individual elements have not been successful and it is therefore hard to prove the usefulness and the realism of the model. 
The car-following models presented by Brackstone and McDonald (1999) are based on the knowledge and input from the time when they were developed. In more recent years, many of the aforementioned car-following models have been extended and improved based on new knowledge and more precise vehicle data with the ability to reflect individual vehicle behaviour. Examples of more recent models proposed in the literature to better reflect the complex behaviour of drivers are the models proposed by Treiber et al. (2000) and Newell (2002). One assumption which has been questioned in the aforementioned car-following models is the assumption that a driver only take one vehicle in front into account when deciding on desired speed. An extension of the GHR model, including multi-leader stimuli, was proposed already in 1968 (Bexelius, 1968). Lately, when calibration through vehicle trajectory data are available, a number of papers have proposed car-following models incorporating multi-leader stimuli based on empirical data. Examples of such papers are Lenz et al. (1999) and Treiber et al. (2005) and Hoogendoorn et al. (2006). Another type of more recent car-following models are the fuzzy logic based models, such as for example the rule based model using a neural network approach as proposed by Chong et al. (2013). The models are the result of today's more powerful computers, allowing for a detailed level of modelling of each vehicle in the simulation. Finally, the need for evaluation of systems based on communication and information to and from the vehicles has resulted in car-following models extended to allow modelling of vehicle behaviour with these new types of in-vehicle systems. In Hoogendoorn et al. (2013), a car-following model is extended to model driver distraction as a result of performing multiple tasks based on information from in-vehicle systems. Tang et al. (2014) extend a car-following model to allow for communication to and from vehicles during an accident.

The lane-changing model regulate if and how the vehicle should behave in case of a lane-change situation. A comprehensive overview of existing lane-changing models is given by Rahman et al. (2013). The lane-changing models can be categorized into four types of models: 
rule-based,discrete-choice-based, artificial intelligence and incentivebased. Rule-based and discrete-choice-based models are the ones that are most popular in microscopic traffic simulators. The rule-based models consider first the vehicle subject to a lane-change. If a set of rules are fulfilled the target lane of the vehicle subject to a lane-change is investigated. The main rule is that the gap of the target lane should be large enough to perform a safe lane-change manoeuvre. Examples of rule-based models that are implemented in microscopic traffic simulation tools are developed by Gipps (1986), Rickert et al. (1996), Halati et al. (1997) and Hidas (2005). Other models make use of cellular automata (Rickert et al., 1996) and game theory (Kita, 1999). The discrete-choicebased models consists of mandatory and discretionary lane-changes. Logit and probit models are commonly applied to check for the necessity of a lane-change, the choice of target lane and the gap acceptance. Examples are the models proposed by Ahmed (1999) and Toledo et al. (2003, 2007). The less common artificial intelligence models consists of fuzzy-logic-based models, see e.g. Wu et al. (2000) and Moridpour et al. (2012) and artificial neural network models, see e.g. Dumbuya et al. (2009) and Tomar et al. (2010). In incentive-based models the choice to change lane is based on the desire to change lane. The maximum benefit is used to decide if a lane-change is performed or not. This is similar to discrete-choice-based models but with the difference that only one utility is calculated and used to decide on the maximal benefit. Example of such models are the mobile by Kesting et al. (2007) and the Lane-changing Model with Relaxation and Synchronization (LMRS) by Schakel et al. (2012).

According to Rahman et al. (2013) there are a number of issues with the existing lane-changing models. For example existing models do not include the planning ahead and anticipation in time of the drivers, the actual process of performing a lane-change, the geometry and the environmental conditions. Further, evaluations of how well the lanechanging models perform are usually based on macroscopic traffic data. Whereas, in order to have reliable models, calibration and validation against microscopic traffic data is needed. 
Apart from the two fundamental core models used in every microscopic traffic simulation model, each tool has its own modelling language, modelling options, and degree of freedom when performing a simulation. Therefore, when making use of microscopic traffic simulation the knowledge of the specific simulation tool is important. The simulation environment is a simplified version of the reality and assumptions leading to how well it reflects reality, how the simulation results can be interpreted, etc., are important for the success of a simulation study.

\subsection{SUMO}

The microscopic traffic simulation tool Simulation of Urban MObility (SUMO) (Krajzewicz et al., 2012; DLR and contributors, 2017) has been continuously developed since 2001 by the Institute of Transportation Systems at the German Aerospace Center. The tool is open source with contributions from the users of the tool. The current version of SUMO is multi-modal, space continuous and time discrete. A Traffic Control Interface ( $\mathrm{TraCI}$ ) enables communication between SUMO and externally developed scripts. This makes it possible to incorporate new applications in the simulation without changing the source code.

The number of SUMO users have increased since the start (Krajzewicz, 2013) and today SUMO is used in many microscopic traffic simulation studies in the research community. The open source has made it easy to couple SUMO with a network simulator, which makes it possible to realistically simulate the transmission of information between vehicles, and between vehicles and the infrastructure. This is of special interest for modelling of communication and information based systems where lost information can decrease the performance of the system. Examples of such studies are given by Schumacher et al. (2009) and Sommer et al. (2008). Further, SUMO is frequently used for evaluation of traffic signal control systems, see e.g. Krajzewicz et al. (2005) and Zubillaga et al. (2014). Another area where SUMO is used is for evaluation of autonomous vehicles, see e.g. Fernandes and Nunes (2010). 


\subsubsection{Car-following}

In SUMO the default car-following model is a space continuous and time discrete model described by Krauß (1998). However, other models are available and it is also possible to implement new car-following models. The model by Krauß (1998) is classified as a safe distance model and parallels the underlining approach proposed by Gipps (1981), in which braking distances are the main consideration. The idea is that the final speed in which a vehicle travels in, i.e. the desired speed, is the minimum of: (1) the maximum speed the vehicle can drive in, or are allowed to drive in, (2) the speed using the vehicle's maximum acceleration ability and (3) a safe speed which allows the vehicle to drive in a safe way without collisions. A lower and upper bound is limiting the acceleration and deceleration possibilities. A difference compared to the original Gipps-model is the assumption that the driver is not perfect in holding its desired speed (Ranjitkar et al., 2005). This driver imperfection is modelled as a stochastic deceleration, as the drivers are assumed to drive with a final speed that is somewhat lower than the desired speed. The driver imperfection is uniformly distributed around the vehicles's maximum acceleration and taking the assumed degree of imperfection into account. Some further extension has been made to the original Gipps-model:

- The ability of accelerating is decreasing with increasing speed (modelled using a linear function).

- The driver's imperfection is reduced when accelerating from low velocities (two cases is considered depending on the vehicle's speed).

The car-following model is described and discussed in detail in Krauß (1998) and Barceló (2010).

\subsubsection{Lane-changing}

The lane-changing model has been continuously developed since the first version of SUMO. The current model from 2013 (Erdmann, 2015) is 
rule based and takes the drivers' route and lane-changing requirements into account in order to be able to continue on the selected route to the vehicle's given destination. From here on the considered vehicle for a possible lane-change is referred to as the ego vehicle. Two conditions has to be fulfilled to perform a lane-change: (1) it has to be enough space on the target lane and (2) the ego vehicle should not come too close to the blocking leader or the blocking follower after the lane-change.

The lane-changing model consists of four parts; the strategic lanechanging, the cooperative lane-changing, the tactical lane-changing and the obligation to clear the overtaking lane. Additionally, the TraCI can be used to directly control the lane-changing manoeuvres. This control is incorporated with the existing lane-changing model and the urgency and the priority to change lane is used as control input.

Strategic lane-changing means planing of lane-changes well in advance in order to avoid reaching a dead lane, where a dead lane is defined as a lane on which the ego vehicle can not continue its predefined route. This corresponds to finding the best lanes along the ego vehicle's route. The best lanes are defined as the lanes where as few lane-changes as possible are done before reaching the next dead lane or up until a maximum distance and by also considering the current traffic density along the identified sequences of lanes. The final strategically advisable direction is based on maximization of the drivable distance and minimization of the number of lane changes. After finding the strategically advisable direction, the urgency of performing a lane-change is calculated. While approaching a dead-end on a dead lane the need to perform a lane-change becomes more urgent. Hence, the urgency of performing a lane-change is based on; (1) the distance to the dead-end, (2) the ego's presumed speed when approaching the dead-end, based on the current and historical speeds of the ego vehicle, (3) the number of lane-changes to reach the strategically advisable lane, (4) occupation on the current lane, (5) occupation on the lane next to the current lane and in direction of the strategically advisable lane. In some cases speed adjustments of the ego vehicle, the follower and/or the leader are performed to be able to have a smoother lane-change. This is the case when the ego vehicle 
are blocked by the follower and/or the leader. In SUMO a random deceleration is added to the desired acceleration in the car-following model, to model driver imperfection. When speed adjustments are needed the driver imperfection is prevented so that the vehicles can use their maximal desired acceleration. The speed adjustments are done by not speeding up or accelerating to reach the maximum speed based on if it is possible for the leader and the follower to overtake the ego or not. According to Erdmann (2015), situations occurs which are not resolvable resulting in deadlocks. This happens when two vehicles need to change lane at the same time and in opposite directions. These situations will also occur in real traffic but are not as abrupt as in the model and will eventually be solved by the drivers. The only way to solve this in the simulation is by the use of teleporting, meaning that a vehicle is transported with its desired speed to the next available position where it can be inserted into the network again. The time before teleporting is set by a treshold. Additional actions to prevent this types of deadlocks in the simulation are: (1) adjustments of the speeds for the two considered vehicles to leave enough space for the leader to change lane, (2) extra space is reserved in front of the vehicle at the dead-end whenever they need to change over more than one lane.

Cooperative lane-changing occur when the ego vehicle is leaving space by changing lane to help vehicles that want to change lane to the current lane of the ego vehicle. In this case, the ego vehicle might change lane in any direction to increase the gap for other lane-changing vehicles, given that there is no blocking on the opposite lanes. Further, the ego vehicle might adjust the speed slightly to be able to change lane at a later time step.

In tactical lane-changing, the utility of taking over a slower vehicle in front is considered. This is of special interest when the speed of the slower vehicle is only slightly lower than the speed of the ego vehicle. A speed gain probability is calculated based on the speed difference and an assumed eagerness to perform lane-changes. The speed gain probability is compared to a threshold value to decide if a lane-change should be performed or not. The speed gain probability to change right 
is further adjusted by an assumption of the eagerness to keep right. In this way, slower moving vehicles, such as trucks, can have a lower desire to change lane and stay in the rightmost lane more frequently.

In many countries it is obligatory to drive in the rightmost lane if not overtaking. Hence, the ego vehicle is only driving in the overtaking lanes if the expected time in the right lane before changing-lane is lower than a threshold.

The necessary decision steps and its hierarchy are summarized in Figure 4.1.

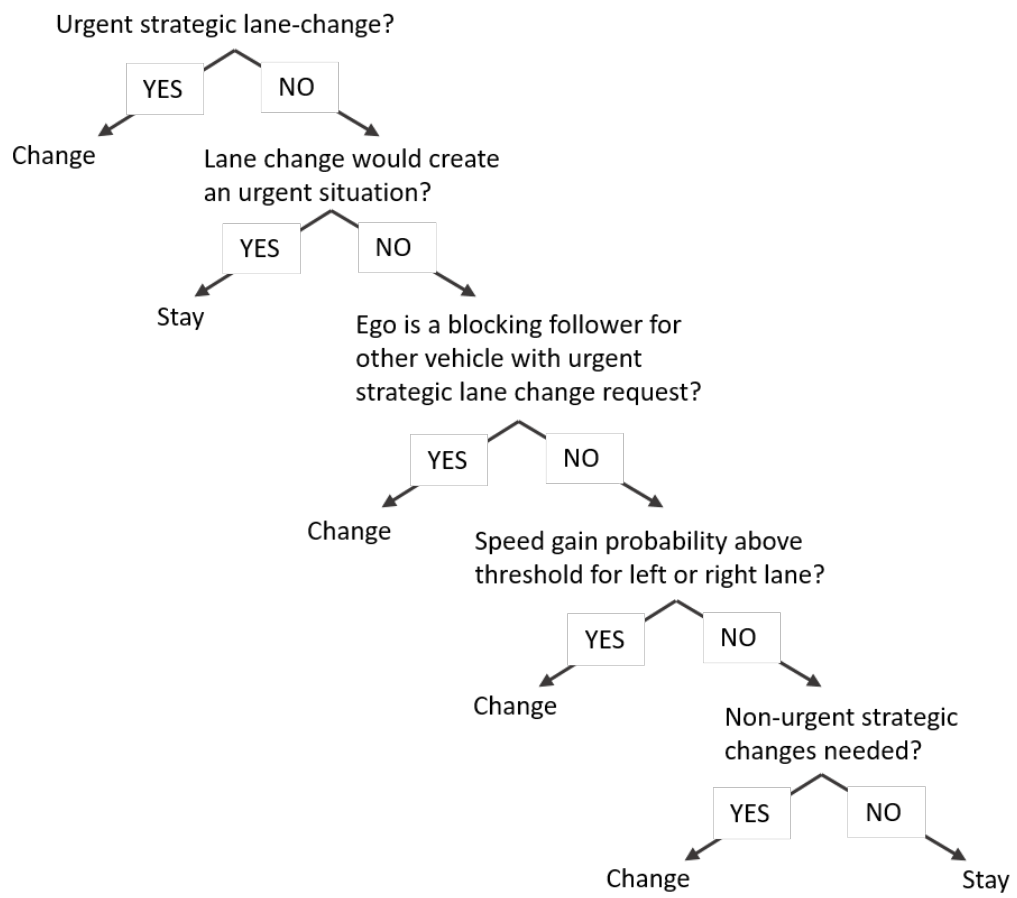

Figure 4.1: Hierarchy of decisions and an illustration of the definitions of vehicles and the road segments in the lane-changing model.

For a detailed description of the lane-changing model see Krajzewicz (2011), Erdmann (2015) and DLR and contributors (2017). 


\subsection{Microscopic traffic simulation applied to VSL systems}

Traffic simulation is a common approach for analysing and evaluation of VSL systems. Typically the studies from the literature focus on the design of the control algorithm. The aim of the control algorithm is usually to improve safety (Abdel-Aty et al., 2006; Lee et al., 2006; Allaby et al., 2007; Piao and McDonald, 2008; Hellinga and Mandelzys, 2011) , efficiency (Zhicai et al., 2004; Hegyi et al., 2008; Torday et al., 2011; Carlson et al., 2011; Carlson et al., 2013) or to reduce environmental impacts (Torday et al., 2011). Many of the studies show that the design of the VSL control strategies is a trade-off between safety and travel time (Zhicai et al., 2004; Lee et al., 2004; Allaby et al., 2007; Abdel-Aty et al., 2006; Lee et al., 2006). Further, Abdel-Aty et al. (2006) show that for high traffic volumes the VSL system does not have any effect on traffic efficiency. On the other hand, the opposite have been shown in Torday et al. (2011). Also, a decrease in safety benefits for low flows has been discussed in Allaby et al. (2007). Finally, Hellinga and Mandelzys (2011) show that the compliance level affect the success of the control strategy. The simulation based studies are in many cases based on existing or improved control strategies, where a reduction of the speed limit is based on threshold values. Some exceptions are Lee et al. (2006) and Hegyi et al. (2008) and Carlson et al. (2011) where new methods for deciding on suitable VSL are proposed. Lu et al. (2011) and Carlson et al. (2012) and Zhang et al. (2006) combine VSL system with a ramp metering system. It is shown that VSL systems are only effective up to a certain point, i.e. vehicles cannot disappear and by lowering the speed limit the vehicles are still present in the traffic system. If the traffic flow becomes very high this will eventually lead to a breakdown. By also incorporating ramp metering, the inflow on the motorway can be controlled even further, resulting in additional improvements.

The above mentioned studies consists of VSL systems using virtual detector measurements from the simulation tool, and the control strategy is calculated outside of the traffic simulation tool and applied 
through some communication interface. The control strategy is applied by changing the allowed speed limit on the road sections. This means that there are no requirements for accessing information from, or control of, individual vehicles in the simulation and the main reason for choosing a microscopic traffic simulation tool is in many cases to be able to model the interactions between vehicles. This is because the main goal with many of the VSL systems is to make the traffic flow more homogeneous, which can not be realistic modelled if the interactions between vehicles are not included.

The use of data from, and control of, connected vehicles does require identification of individual vehicles within the simulations. Since microscopic traffic simulators can model individual interactions of the vehicles within the simulation, it is needed for evaluations of VSL systems including connected vehicles. This is also shown in the literature in Section 3.3 where the simulation based studies of VSL system including connected vehicles are using microscopic traffic simulation, see e.g. Yang and Jin (2014), Kattan et al. (2015), Khondaker and Kattan (2015a), Wang et al. (2016) and Müller et al. (2016). The connected vehicles are commonly used as detectors and the microscopic traffic simulation tool is used together with an interface for communication of individual vehicle data during the simulation process (Yang and Jin, 2014; Kattan et al., 2015; Khondaker and Kattan, 2015a). The information is processed outside of the microscopic traffic simulator and the control strategy is displayed on variable message signs. However, the connected vehicles can also be used for direct control, with the given speed limit as control input, to increase the compliance of the control strategy (Wang et al., 2016; Müller et al., 2016). In this case, the speed limit is calculated based on a control algorithm with data gathered from stationary detectors. 


\section{Chapter 5}

\section{The present thesis}

Motorway traffic management systems have been proven to be useful for improving the traffic situation on urban motorways, with Variable Speed Limit (VSL) systems being one of the most commonly applied systems. One observed limitation of existing VSL systems are delayed detection of incidents resulting in that the control strategy is applied too late. The reason for this is that measurements of the traffic conditions are only available from stationary detectors at fixed locations, usually with a distance of 300-1000 meters in between them. Further, updates of the speed limit are visible to the drivers only at discrete locations and the drivers that are in between these locations are unable to receive the updates. Finally, implemented VSL systems are usually based on thresholds and the speed limits are lowered with a fixed amount, often leading to an inefficient control strategy due to the large speed limit reductions.

The introduction of connected vehicles in today's traffic systems has contributed to a new source of information, which can be used for estimating the traffic conditions at arbitrary locations. Further, information can be given to the connected vehicles independent of location. Hence, connected vehicles can be used to improve existing VSL systems and to develop new types of VSL systems. To exploit this potential, 
additional research is needed. First, since most existing control algorithms in VSL systems implemented in real traffic are threshold based with the main goal to increase safety, the effects on traffic efficiency is limited or even negative. More studies are needed to draw conclusions about desirable characteristics when designing VSL control algorithms with the main goal to increase traffic efficiency. Second, as concluded in Chapter 3, connected vehicles can contribute to improvements in the traffic state estimation, and in the application of speed limits through information to or control of individual vehicles. This has to be further explored to find good methods using connected vehicles in VSL systems for traffic state estimation and for application of the speed limits. Finally, connected vehicles have been proposed to be used in VSL systems, either for estimation of the traffic conditions or for control of individual vehicles. If the connected vehicles are used for traffic state estimation, the estimates are input to the control algorithm in order to find speed limits to be displayed on variable message signs. When the connected vehicles are used for control of individual vehicles, existing VSL systems with densely placed detectors are used to measure and estimate the traffic state. The benefits of applying a VSL system using connected vehicles both for the traffic state estimation, and for control of individual vehicles at arbitrary locations, have this far not been concluded. These benefits have the potential to greatly reduce the need for stationary infrastructure, such as variable message signs and stationary detectors.

\subsection{Objectives}

The objective of this thesis is to examine how connected vehicles in VSL systems can contribute to improved traffic efficiency. The following research questions are stated:

1 Are the use of VSL systems a beneficial traffic management strategy on urban motorways when the goal is to increase traffic efficiency? 
2 What are the desirable characteristics to include in a VSL system and how should the control algorithm be designed?

3 Can the use of connected vehicles in a VSL system improve traffic efficiency?

4 How can connected vehicles be used in the traffic state estimation?

5 How can connected vehicles be used for application of the speed limits?

In order to answer these questions, new and improved methods using connected vehicles are proposed and analysed for the important parts of a VSL system.

\subsection{Research method}

Since the proposed methods and VSL systems are non-existing a preimplementation evaluation method is required. A pre-implementation evaluation gives an indication of how the proposed methods and the VSL systems can perform in real traffic. A common method to use for pre-implementation evaluations is simulation. Simulation is useful to quantify the potential effects of the proposed methods and VSL systems without large-scale field trials or implementations of expensive infrastructure equipment which is a necessity for VSL systems. Further, the resulting effects at different penetration rates of connected vehicles are easily accessible. Therefore, given that the simulation model can mimic real traffic, simulation can be used to answer the research questions.

In this thesis, microscopic traffic simulation is used. The reason for this is that microscopic traffic models include explicit representation of the interactions between individual vehicles in the traffic flow, which is necessary for modelling of connected vehicles that make use of communication to and from individual vehicles. Further, VSL systems are known to contribute to reduced lane-changing manoeuvres leading to flow homogenization and less interactions between individual vehicles 
during lane-changes. These lane-changing interactions between individual vehicles can only be modelled in microscopic traffic simulators. The proposed methods and VSL systems are implemented in an urban motorway simulation environment and statistical methods are used to quantify the effects of the simulated output and for comparisons of the resulting performance of the proposed methods and VSL systems. Examples of performance indicators are mean speed, travel time, standard deviation of speed and acceleration distributions. The microscopic traffic simulation tool SUMO (Krajzewicz et al., 2012; DLR and contributors, 2017) is used throughout this thesis.

In some of the papers, other well-known techniques from the literature are also used. Paper II is using the Newtonian mechanics equations of motion to find individual speed limits. In Paper V and VI data assimilation, ensemble Kalman filtering and traffic flow theory is used to estimate the traffic flow parameters and for finding a suitable control strategy.

\section{$5 \cdot 3$ Delimitations}

The main goal in this thesis is the use of connected vehicles in VSL systems to increase traffic efficiency. This might indirectly lead to increased traffic safety and reduced environmental impacts as well. However, to increase traffic safety and reduce environmental impacts is not the focus of this thesis.

The focus is on straightforward VSL control algorithms suitable for implementation in real traffic. However, more complex algorithms exists in the literature, but is not the subject of this thesis.

In Paper I, which is a case study, the simulation model is built and calibrated using real data. The other papers makes use of fictive networks to isolate the effects of the investigated methods.

The thesis assume perfect communication between vehicles and vehicles and the infrastructure. Hence, limitations of the systems due to lost and delayed information as a result of limitations in the communication technologies are not studied. 


\subsection{Contributions}

The present thesis makes the following contributions:

- Identifies the important parts to consider when designing VSL systems, with and without connected vehicles.

- Establishes how connected vehicles can contribute to improvements of a VSL system. This is done by exploring how connected vehicles can be incorporated in the traffic state estimation, the design of the control algorithm and the infrastructure for application of speed limits.

- Shows that the use of VSL systems are promising traffic management strategies and good alternatives to increasing capacity by expanding the land use on urban motorway stretches, exemplified for a Stockholm case.

- Identifies desirable characteristics of a VSL control algorithm.

- Proposes methods for incorporating connected vehicles and sparsely placed detectors in the traffic state estimation and for estimation of the traffic flow parameters, such as jam density, capacity, free flow speed, etc. A precise estimation of the traffic state and the traffic flow parameters allow for application of an accurate VSL control strategy.

- Concludes that connected vehicles can contribute to identification of bottlenecks at arbitrary locations. This is required in order to apply a control strategy with the aim to increase efficiency. Additionally, an estimation of the magnitude of the changes in important target values, such as the capacity, is done.

- Quantifies the accuracy of the proposed method for traffic state estimation and show that it is comparable to similar methods, but with the benefit of having less demand for expensive infrastructure equipment.

- Confirms that the results of the real-time calibration of the model parameters of a dynamic traffic model can be used for finding 
time dependent traffic flow parameters at a non-recurrent bottleneck. It is verified by concluding that the real-time calibration of the traffic flow parameters in a first-order traffic model correspond to the empirical fundamental relations in the simulated experiment.

- Develops two VSL control strategies based on direct control of the speed limit of connected vehicles. Limitations with introducing $\mathrm{I} 2 \mathrm{~V}$ in an existing VSL system are concluded. Improvements are suggested by incorporating a proposed method for traffic state estimation using connected vehicles and a more suitable control algorithm.

\subsection{Included papers}

The six papers included in the thesis contribute with elements of knowledge that are necessary for a well-designed VSL system using connected vehicles. Paper I and II contribute with knowledge and background to the usefulness of VSL systems and the application of connected vehicles in an existing VSL system. It is shown that VSL systems can effectively improve the traffic conditions during congestion at urban motorways. Further, the use of connected vehicles in an existing VSL system with a simple threshold based algorithm, result in homogenization effects. However, no improvements are seen in terms of traffic efficiency. This implies that a more sophisticated VSL algorithm is needed to improve traffic efficiency. The conclusions and observations from the first two papers are the foundation for the work presented in Paper III-VI. Paper III gives an in-depth evaluation of the design of the control algorithm used in VSL systems. The purpose is to find desirable characteristics of a control algorithm. By comparing algorithms from the literature and implemented in real traffic, it is concluded that the aim and the level of detail in estimating the traffic conditions have a great influence on the traffic performance. Hence, in order to improve the performance of a VSL algorithm, an accurate estimate of the traffic state and the parameters used as input to the control algorithm are 
of importance. By introducing connected vehicles in the traffic state estimation, information about the vehicle's speed and position can be communicated frequently and at arbitrary locations. Methods for estimating the traffic state and the traffic flow parameters using connected vehicles are proposed in Paper IV and V. The final paper propose a VSL system using connected vehicles by incorporating the methods from Paper IV and V and application of the speed limits by direct control of the connected vehicles. The control algorithm is based on an extension of one of the control algorithms from Paper III. Summaries of the included papers are given below.

\section{Paper I: Urban motorway bottleneck mitigation - a Stockholm case study}

Paper I investigates the effect of applying different traffic management strategies to an urban motorway stretch in Stockholm. The motorway stretch is experiencing congestion during peak-hours why different traffic management strategies are important in order to improve traffic efficiency. Three different VSL algorithms are compared to changes of the road infrastructure. The considered road stretch have homogeneous traffic conditions and consists of two on-ramps and two off-ramps, which makes it easy to isolate the bottleneck locations and the related effects. This makes it ideal for investigations of different traffic management strategies. Microscopic traffic simulation is used for evaluation of the different measures. The road stretch is calibrated against real traffic data. It is concluded that increasing the capacity by adding one lane is, not surprisingly, the best alternative. However, some of the VSL strategies manage to decrease travel time and increase mean speed in the same range as reconstruction of the road infrastructure by adding one lane. The main reason for this is that by lowering the speed limit the ability of performing lane-changes increase and incidents as a result of lane-changes at bottlenecks are reduced. However, the speed limit changes must reflect the prevailing traffic conditions in order to be effective. The main benefits of applying 
VSL systems compared to expanding the infrastructure is the usually smaller investment and maintenance costs and the possibility to increase efficiency without increasing the land-use, which is sometimes impossible. As a conclusion, VSL systems are promising alternatives for traffic management purposes. The results in this paper are the foundation for Paper II-VI since it shows the usefulness of VSL systems as a motorway control strategy.

The paper is co-authored by Andreas Tapani. The author of this thesis has contributed as the main author and by taking the main responsibility for research planning, implementation, simulation and analysis. The co-author has contributed with input to the research planning, the implementation, the simulation and the analysis. The writing of the article has been a joint responsibility, where the author of this thesis had the leading role.

Paper I is submitted to

- Case studies on transport policy, February, 2018

Parts of the contents in Paper I have been presented at

- Transportforum, Linköping, Sweden, 2018

\section{Paper II: Analysis of a cooperative variable speed limit system using microscopic traffic simulation}

As a result of the increasing amount of available technology, existing VSL systems can be improved by incorporation of cooperative systems using connected vehicles. Paper II introduce an extension of an existing threshold based VSL system by including I2V communication, autonomous vehicle control and individualized speed limits. The traffic state is estimated using stationary detectors. In the proposed system, a roadside unit is used to communicate the current speed limits to upstream vehicles before the variable message signs become visible to the drivers. The vehicles adapt their speed to the oncoming VSL by considering the speed of the vehicle itself, the speed of the VSL and 
the distance between the vehicle and the considered VSL. No interaction between the vehicle and the driver is considered, i.e. the system acts similar to an adaptive cruise control. Microscopic traffic simulation is used for evaluation of the proposed system and for comparison with a regular VSL system without incorporating connected vehicles. The two VSL systems are applied to an active bottleneck, modelled as a lane drop, to get an activation of the system. The analysis show that the main benefits with the introduced cooperative VSL system are a more homogeneous flow as a result of lower levels of high accelerations. This in turn is resulting in lower emissions levels. However, no large effects are seen on speed. Further, it is concluded that the choice of control algorithm for deciding the speed limit is of great importance for the performance of the system. A threshold based VSL system reduce the possibility to improvements in traffic efficiency when using connected vehicles in the system. This is in line with Paper I where it is concluded that only the algorithms that are adjusting the speed limits based on the prevailing traffic conditions manage to increase traffic efficiency. Hence, as a next step it is important to find the desirable characteristics to include in a VSL system.

The paper is co-authored by Xiaoliang Ma and Andreas Tapani. The author of this thesis has contributed as the main author and by taking the main responsibility for research planning, development of the cooperative VSL system, simulation and analysis. Xiaoliang Ma has been the main contributor to the part focusing on the environmental impacts. Both co-authors have been involved in the research planning and the analysis, and contributed with input to the implementation and the simulation. The writing of the article has been a joint responsibility.

Paper II is published in

- Transportation research part C: Emerging technologies, 2015, Vol. 52, pp. 173-186.

Parts of the contents in Paper II have been presented at

- Transportforum, Linköping, Sweden, 2012 
- 8th International Conference on Traffic and Transportation Studies (ICTTS), 2012

- 1st SUMO user conference, Berlin, Germany, 2013

- Swedish transport research conference, Gothenburg, Sweden, October, 2013

and published in

- Grumert, E. Ma, X. and Tapani, A., Impacts of a cooperative variable speed limit system, Procedia - Social and Behavioral Sciences, 2012, Vol. 43, pp. 595-606.

- Grumert, E., Ma, X. and Tapani, A. (2013). Effects of a Cooperative Variable Speed Limit System on Traffic Performance and Exhaust Emissions. In Transportation Research Board $92^{\text {th }}$ annual meeting, Compendium of papers, No. 13-4014

- Grumert, E. and Tapani, A. (2013). Microscopic traffic simulation for evaluation of a cooperative variable speed limit system. In Reports of the DLR-Institute of Transportation Systems, Proceedings of the $1^{\text {st }}$ SUMO user conference, Berlin, Germany, Vol. 21, pp. 147163.

- Grumert, E. (2014). Cooperative variable speed limit systems Modeling and evaluation using microscopic traffic simulation. Licentiate thesis in Linköping Studies in Science and Technology, No. 1670, Linköping University, Sweden.

\section{Paper III: Characteristics of variable speed limit systems}

As concluded in Paper I and II, the performance of a VSL system is influenced by the algorithm for deciding on the speed limit to be applied. Therefore, in Paper III, the performances of four different control algorithms used in a VSL system are investigated. That is, traditional VSL 
systems, without the use of connected vehicles, are considered. The considered control algorithms do have different defined objectives and include different measures as representation of the traffic conditions and the traffic flow parameters. The control algorithms are evaluated by the use of microscopic traffic simulation. A fictive road stretch with a simple design is modelled to isolate the effects of the different algorithms. A bottleneck is created by reducing the number of lanes from two to one to activate the different algorithms. The performance is evaluated by means of traffic safety, traffic efficiency and environmental impacts. It is concluded that the level of detail and the aspects included in the control algorithm for estimation of the traffic conditions affect the performance of the VSL system. Moreover, the time needed for incident detection, the duration and the size of the speed limit reduction, and the location of the congestion are factors of importance for the performance of the VSL system. Hence, an accurate traffic state estimation and identification of the traffic flow parameters are relevant when designing a VSL algorithm. One algorithm, based on control theory, is aiming for improved traffic efficiency. The algorithm show promising results and is further used in Paper VI as the control algorithm in a VSL system using connected vehicles.

The paper is co-authored by Andreas Tapani and Xiaoliang Ma. The author of this thesis has contributed as the main author and by taking the main responsibility for research planning, implementation of the control algorithms, simulation and analysis. Xiaoliang Ma has been the main contributor to the part focusing on the environmental impacts. Both co-authors have been involved in the research planning and the analysis, and contributed with input to the implementation and the simulation. The writing of the article has been a joint responsibility.

Paper III is accepted for publication in

- European transport research review, 2018

Parts of the contents in Paper III have been presented at

- Swedish transport research conference, Gothenburg, Sweden, October, 2014 
- Transportforum, Linköping, Sweden, 2015

- Transportation Research Board 95 ${ }^{\text {th }}$ annual meeting, Washington, U.S., 2016

and published in

- Grumert, E. (2014). Cooperative variable speed limit systems Modeling and evaluation using microscopic traffic simulation. Licentiate thesis in Linköping Studies in Science and Technology, No. 1670, Linköping University, Sweden.

- Grumert, E. Ma, X. and Tapani, A., Evaluation of four control algorithms used in variable speed limit systems. (2016) In Transportation Research Board $85^{\text {th }}$ annual meeting, Compendium of papers, No 16-2880.

- Allström, A., Barceló J., Ekström, J., Grumert, E., Gundlegård, D., and Rydergren, C. (2016), Traffic management for smart cities, In: Angelakis, v., Tragos, E., Pohls, H.C., Kapovits, A. and Bassi, A. eds, Designing, developing and facilitating smart cities: urban design to IoT solutions, Switzerland: Springer, pp. 211-240.

\section{Paper IV: Traffic State Estimation Using Connected Vehicles and Stationary Detectors}

Traffic state estimation is one of the important parts in a VSL system. Further, Paper III conclude that an accurate traffic state estimation is important for the performance of a VSL system. Paper IV propose the Count Connected Vehicle (CCV) method, using connected vehicles and sparsely placed stationary detectors, for estimating the traffic state. The penetration rate of connected vehicles is estimated based on stationary detector measurements. The number of connected vehicles for a sub-segment of the road stretch is estimated by collecting information about the connected vehicles' position. The penetration rate together with an estimate of the number of connected vehicles on a road segment is used to find the density for each road segment. The speed is 
estimated using the speed of the connected vehicles. The method is applied to a fictive road stretch using microscopic traffic simulation. The accuracy is evaluated by comparing the traffic state estimates using the proposed method with traffic state estimates from other methods. The method manage to estimate the traffic state with the same accuracy as another similar method proposed in the literature. At higher penetration rates the results are also comparable to using a simple stationary detector based method. The main benefit with the proposed method is that it is independent of closely located stationary detectors, i.e. the investments in expensive infrastructure is reduced. Further, by using connected vehicles it is possible to detect the traffic state also in between detectors, which makes the method suitable for finding incidents as a result of non-recurrent bottlenecks at arbitrary positions where the application of VSLs can be useful. The method suggested in this paper is used as input to the estimation of the time dependent traffic flow parameters at arbitrary segments in Paper V and as part of the VSL system in Paper VI.

The paper is co-authored by Andreas Tapani. The author of this thesis has contributed as the main author and by taking the main responsibility for research planning, development of a new method, modelling, simulation and analysis. The co-author has contributed with input to the research planning, the development of a new method, the implementation, the simulation and the analysis. The writing of the article has been a joint responsibility, where the author of this thesis has taken the leading role.

Paper IV is published in

- Journal of advanced transportation, Vol. 2018, 14 pages.

Parts of the contents in Paper IV have been presented at

- Swedish transport research conference, Gothenburg, Sweden, October, 2016

- Transportforum, Linköping, Sweden, 2017 


\section{Paper V: Real-time estimation of the parameters in a fundamental diagram using connected vehicles}

In order to apply an appropriate VSL control strategy the magnitude of the changes in the traffic state, as well as the parameters used as input in the control algorithm, are required. One way of detecting changes in the traffic state is to estimate and identify changes in the traffic flow parameters, defined as jam density, critical density, free flow speed, etc. Further, the traffic flow parameters can be used as parameters in the control algorithm. Paper V contribute to dynamic motorway traffic control by proposing a method for estimating the traffic flow parameters, which can be used as input in the control algorithm. The proposed method make use of a traffic model to describe the evolution of traffic over time and an ensemble Kalman filter. The traffic model is based on the first-order cell transmission model together with the triangular fundamental diagram for describing the relation between speed, flow and density. The ensemble Kalman filter is used for real-time calibration of the parameters in the triangular fundamental diagram. The parameters of the modelled traffic state are adjusted to the estimated traffic state based on measurements using the method proposed in Paper IV. The method is applied to a fictive road stretch and using microscopic traffic simulation. The accuracy of the method is evaluated by comparing the estimated parameters to the empirical fundamental relations for three different common situations at urban motorways resulting in a non-recurrent or recurrent bottleneck. The method manage to identify changes in the traffic state and to correctly estimate the traffic flow parameters when the bottleneck is the result of an incident and a speed reduction. However, at an on-ramp it is harder to estimate the traffic flow parameters correctly. The proposed method in this paper is used to estimate the critical density, which is used as input to control algorithm of the VSL system proposed in Paper VI.

The paper is co-authored by Andreas Tapani. The author of this thesis has contributed as the main author and by taking the main responsibility for research planning, development of the method, modelling, simulation and analysis. The co-author has contributed with input to 
the research planning, the development of the method, the implementation, the simulation and the analysis. The writing of the article has been a joint responsibility, where the author of this thesis has taken the leading role.

Paper $\mathrm{V}$ is submitted to

- Transportation Research Part C and the special issue Sensing, Modeling and Control of Connected and Automated Vehicle-Traffic Systems, March 2018.

Parts of the contents in Paper V have been presented at

- Swedish transport research conference, Gothenburg, Sweden, October, 2017

\section{Paper VI: Non-recurrent bottleneck mitigation through a variable speed limit system using connected vehicles}

In Paper VI a VSL system using connected vehicles is proposed for application of variable speed limits at non-recurrent bottlenecks. The methods from Paper IV and V, using V2I communication, are used to estimate the time dependent traffic state and the critical density, respectively. The estimates are used as input to the traffic efficiency enhancing control algorithm identified in Paper III. Thereby, the control algorithm is extended to deal with application of variable speed limits at arbitrary road segments and for non-recurrent bottlenecks. I2V communication is used for communicating the current speed limit to the connected vehicles. Automatic control is applied, i.e. the connected vehicles are assumed to have in-vehicle systems similar to an adaptive cruise control to adapt to the speed limits. The method is evaluated by microscopic traffic simulation and applied to a fictive road stretch. It is concluded that with a connected vehicle penetration rate of $100 \%$, the method manage to improve the traffic conditions for all of the simulation runs, compared to no control. Consequently, using connected 
vehicles in a VSL system has a large potential of improving traffic efficiency.

The paper is co-authored by Andreas Tapani. The author of this thesis has contributed as the main author and by taking the main responsibility for research planning, development of the VSL algorithm, modelling, simulation and analysis. The co-author has contributed with input to the research planning, the development of the VSL algorithm, the implementation, the simulation and the analysis. The writing of the article has been a joint responsibility, where the author of this thesis has taken the leading role.

Paper VI is submitted to

- Transportmetrica A, January, 2018, by invitation from the EURO Working Group on Transportation meeting (EWGT2017)

Parts of the contents in Paper VI have been presented at

- EURO Working Group of Transportation (EWGT) meeting, Budapest, Hungary, 2017

and published in

- Grumert, E. F. and Tapani, A. (2017). Using connected vehicles in a variable speed limit system, In: Transportation Research Procedia, Vol. 27, 2017, pp. 85-92.

\subsection{Future research}

This thesis contribute with knowledge and methods that have impact on the introduction of connected vehicles in VSL systems. However, there are many areas to further explore before the advantages of using connected vehicles in VSL systems and its main components can be definitely concluded.

VSL systems are suitable for reducing negative effects of high traffic flows close to the capacity. However, if the traffic flow is much higher 
than the capacity the effects of VSL systems might be limited. This is creating an inefficient traffic system with very low speed limits in order to keep capacity as high as possible. Instead, ramp metering (Papageorgiou et al., 1991; Gomes and Horowitz, 2006; Meng and Khoo, 2010; Geroliminis et al., 2011; Bhouri et al., 2013) or a combination between ramp metering and variable speed limits might be suitable (Lu et al., 2011; Carlson et al., 2012; Zhang et al., 2006). In this case, the ramp metering is used to reduce the negative impacts of the high traffic flows by limiting the incoming flow to the main road, whilst variable speed limits are used to improve the traffic conditions at the main road by keeping capacity as high as possible with reasonable speed limit reductions. Hence, to study the effect of combined ramp metering and VSL systems using connected vehicles at traffic flows much higher than the capacity is an interesting subject for future research.

The density estimation method proposed in Paper IV is based on an estimate of the penetration rate of connected vehicles at sparsely placed detectors. More advanced methods for estimating the penetration rate can possibly improve the performance of the density estimation. For example the penetration rates between the detectors can be estimated based on data assimilation and fusion techniques similar to what is proposed in Bekiaris-Liberis et al. (2016). In this way measurements from the connected vehicles can contribute with more information additional to the measurements from the stationary detectors.

One of the most critical issue of urban motorways during peakhours are the many lane-changes. These are concluded to result in a capacity drop, which is the result of the limited ability to accelerate when performing lane-changes (Laval and Daganzo, 2006). Hence, by making it easier to change lane before entering the bottlenecks, the traffic efficiency can be increased. In this thesis, VSL systems are proposed to make the traffic flow more homogeneous around the bottleneck by lowering the speed limit to reduce the difference in speed. An alternative could be lane-control by directing vehicles to the most suitable lane before arriving to the bottleneck, i.e. vehicles that do not need to be in the lane-changing area are directed to passing lanes when reach- 
ing the bottleneck. By performing such planned lane-changes earlier in time, unnecessary lane-changes can be avoided. Hence, to incorporate lane-change control in a VSL system, similar to what has been done in Zhang and Ioannou (2016) could possibly improve traffic efficiency even more. A next step is to investigate the effects of also including lane-change control into the VSL system proposed in Paper VI.

A natural next step would be to apply the VSL system proposed in Paper VI to a real traffic case similar to the Stockholm case considered in Paper I. The complexity of the network can increase the possibility to harmonize the traffic flow and thereby increase traffic efficiency even further, but it can also create new problems not taken into account in the fictive network.

Connected vehicles are not commonly existing in real traffic or are limited to a small portion of the current vehicle fleet. Therefore, the user-behaviour of drivers using systems including connected vehicles has not been explored much. More research is needed to evaluate which effect the systems will have on the drivers, for example through field tests and using driving simulator based tests. This is an important input to increase the reliability of the assumed behaviour of the drivers in the microscopic traffic simulation model. Further, high compliance and acceptance are necessary to have an effect of the systems, why it is important to understand how the users will perceive the VSL systems suggested in this thesis.

Paper V and VI does only consider a $100 \%$ penetration rate. A lower penetration rate will affect the performance and this has to be further investigated. In this case, the distribution of speeds for the connected vehicles may differ from the distribution of speeds for the nonconnected vehicles, which has to be considered in the macroscopic traffic model.

In dense networks, the communicated information from and to connected vehicles might get lost or delayed, which in turn will decrease the performance of the VSL system. According to Darwish and Bakar (2015), many of the studies on traffic state estimation using connected vehicles are focused on issues related to broadcasting protocols and 
performance of information systems. The effects of lost and delayed information on the proposed methods need to be further investigated. This can for example be done by coupling of SUMO and a network simulator similar to what is proposed by Schumacher et al. (2009) and Sommer et al. (2008).

The interest in autonomous vehicles is high and different in-vehicle systems using connected vehicles can be seen as sub-systems in the control of an autonomous vehicle, for example the VSL system proposed in Paper VI. Therefore, it is important to study effects of the proposed system given that the vehicles are autonomous vehicles.

Finally, the focus of the research presented in this thesis is on Variable Speed Limit (VSL) systems, but most of the proposed methods are applicable to other types of traffic management systems. One example is ramp metering, where traffic state estimation and real-time calibration of the traffic flow parameters can be used to find a control strategy that allow an optimal traffic flow to enter the main road. Another example is route guidance through variable message signs, where traffic state estimation is used to identify bottlenecks in order to suggest alternative routes to avoid the congestion. 



\section{Bibliography}

Abdel-Aty, M, Dilmore, J, and Dhindsa, A (2006). "Evaluation of variable speed limits for real-time freeway safety improvement”. Accident Analysis and Prevention 38.(2), pp. 335-345.

Ahmed, K. I. (1999). "Modeling drivers' acceleration and lane changing behavior". PhD thesis. Cambridge, Massachusetts, United States: Massachusetts Institute of Technology.

Ahn, S. and Cassidy, M. J. (July 2007). "Freeway traffic oscillations and vehicle lane-change maneuvers". In: Proceedings of the 17th International Symposium on Transportation and Traffic Theory (ISTTT17). London, United Kindom.

Allaby, P., Hellinga, B., and Bullock, M. (2007). "Variable speed limits: Safety and operational impacts of a candidate control strategy for freeway applications". IEEE Transactions on Intelligent Transportation Systems 8.(4), pp. 671-680.

Ampountolas, K. and Kouvelas, A. (July 2015). "Real-time estimation of critical vehicle accumulation for maximum network throughput". In: IEEE American Control Conference ACC'15. Chicago, United States, pp. 2057-2062.

Asmaa, O., Mokhtar, K., and Abdelaziz, O. (2013). "Road traffic density estimation using microscopic and macroscopic parameters". Image and Vision Computing 31.(11), pp. 887-894. 
Astarita, V., Bertini, R. L., d'Elia, S., and Guido, G. (2006). "Motorway traffic parameter estimation from mobile phone counts." European Journal of Operational Research 175.(3), pp. 1435-1446.

Barceló, J. (2010). Fundamentals of traffic simulation. Vol. 145. International Series in Operations Research \& Management Science. Springer.

Bekiaris-Liberis, N., Roncoli, C., and Papageorgiou, M. (2016). "Highway Traffic State Estimation With Mixed Connected and Conventional Vehicles." IEEE Transactions on Intelligent Transportation Systems 17.(12), p. 3484.

Berg, S. and Bukkems, N. (Sept. 2001). "Dutch and Swedish experiences of the Dutch Motorway Control System MTM". In: Proceedings of the $8^{\text {th }}$ World Congress on Intelligent Transport Systems. Sydney, Australia.

Bexelius, S. (1968). "An extended model for car-following”. Transportation Research 2.(1), pp. 13-21.

Bhaskar, A., Tsubota, T., Kieu, L. M., and Chung, E. (2014). "Urban traffic state estimation: Fusing point and zone based data". Transportation Research Part C: Emerging Technologies 48, pp. 120-142.

Bhouri, N., Haj-Salem, H., and Kauppila, J. (2013). "Isolated versus coordinated ramp metering: field evaluation results of travel time reliability and traffic impact". Transportation Research Part C: Emerging Technologies 28, pp. 155-167.

Börjesson, M. and Kristoffersson, I. (2015). "The Gothenburg congestion charge. Effects, design and politics”. Transportation Research Part A: Policy and Practice 75, pp. 134-146.

Brackstone, M. and McDonald, M. (1999). "Car-following: A historical review." Transportation Research Part F: Traffic Psychology and Behaviour 2.(4), pp. 181-196. 
Burghout, W. (2004). "Hybrid microscopic-mesoscopic traffic simulation". PhD thesis. Stockholm, Sweden: Royal institute of technology (KTH).

Carlson, R., Papamichail, I., and Papageorgiou, M. (2011). "Local feedback-based mainstream traffic flow control on motorways using variable speed limits". IEEE Transactions on Intelligent Transportation Systems 12.(4), pp. 1261-1276.

Carlson, R. C., Manolis, D., Papamichail, I., and Papageorgiou, M. (2012). "Integrated Ramp Metering and Mainstream Traffic Flow Control on Freeways Using Variable Speed Limits”. Procedia - Social and Behavioral Sciences 48, pp. 1578-1588.

Carlson, R. C., Papamichail, I., and Papageorgiou, M. (2013). "Comparison of Local Feedback Controllers for the Mainstream Traffic Flow on Freeways Using Variable Speed Limits". Journal of Intelligent Transportation Systems: Technology, Planning, and Operations 17.(4), pp. 268-281.

Casas, J., Ferrer, J. L., Garcia, D., Perarnau, J., and Torday, A. (2010). "Traffic Simulation with Aimsun". In: Fundamentals of Traffic Simulation. Ed. by J. Barceló. New York: Springer, pp. 173-232.

Chiou, Y.-C., Huang, Y.-F., and Lin, P.-C. (2012). "Optimal variable speed-limit control under abnormal traffic conditions". Fournal of the Chinese Institute of Engineers 35.(3), pp. 299-308.

Chong, L., Abbas Montasir, M., Flintsch Alejandra, M., and Higgs, B. (2013). "A rule-based neural network approach to model driver naturalisitic behavior in traffic". Transportation Research Part C: Emerging Technologies 32, pp. 207-223.

Chung, K., Rudjanakanoknad, J., and Cassidy, M. J. (2007). "Relation between traffic density and capacity drop at three freeway bottlenecks". Transportation Research Part B: Methodological 41, pp. 8295. 
Clairais, A., Duret, A., and El Faouzi, N.-E. (2016). "Calibration of the fundamental diagram based on loop and probe data." Transportation Research Record: fournal of the Transportation Research Board 2560, pp. 17-25.

Coifman, B. (2003). "Estimating density and lane inflow on a freeway segment". Transportation Research Part A: Policy and Practice 37, pp. 689-701.

COOPERS (2010a). Co-operative Networks for Intelligent Road Safety, D6100, Final report on demonstration. Tech. rep. European commission.

COOPERS (2010b). Homepage: Project COOPERS. Accessed: October 2010. URL: http : / / ww . coopers -ip. eu/index . php ? id= project.

Coppola, R. and Morisio, M. (2016). "Connected Car: Technologies, Issues, Future Trends”. ACM Computing Surveys 49.(3), pp. 1-36.

CVIS (2010). CVIS, Cooperative Urban Mobility. Tech. rep. European Comission.

Dabiri, A. and Kulcsár, B. (2015). "Freeway traffic incident reconstruction: A bi-parameter approach”. Transportation Research Part C: Emerging Technologies 58, pp. 585-597.

Daganzo, C. and Laval, J. (2006). "Lane-changing in traffic streams." Transportation Research Part B: Methodological 40.(3), pp. 251-264.

Darwish, T. and Bakar, K. A. (2015). "Traffic density estimation in vehicular ad hoc networks: A review". Ad Hoc Networks 24 Part A, pp. 337-351.

Den Tonkelaar, W. (1991). Calculation of the optimal driving speed of cars and lorries (minimal emissions and fuel consumption) on highways with different speed limits. Tech. rep. Netherlands: Institute for Road Safety Research, SWOV. 
Dervisoglu, G., Gomes, G., Kwon, J., Muralidharan, A., Varaiya, P., and Horowitz, R. (Jan. 2009). "Automatic Calibration of the Fundamental Diagram and Empirical Observations on Capacity." In: Transportation Research Board $88^{\text {th }}$ annual meeting, Compendium of papers. Washington D.C., United States.

Diebold, J. (1995). Transportation Infostructures:The Development of Intelligent Transportation Systems. Praeger publishers.

DLR and contributors (2017). SUMO homepage. Avaliable at: http: //sumo.dlr.de/wiki/Main_Page.

Drake, J. S., Schofer, J. L., and May Jr, A. D. (1967). "A statistical analysis of speed-density hypotheses. in vehicular traffic science”. Highway Research Record 154, pp. 53-87.

Dumbuya, A., Booth, A., Reed, N., Kirkham, A., Philpott, T., Zhao, J., and Wood, R. (2009). "Complex Systems and Self-organization Modelling. Understanding Complex Systems”. In: ed. by C. Bertelle, G. Duchamp, and H. Kadri-Dahmani. Berlin, Heidelberg: Springer. Chap. Complexity of traffic interactions: Improving behavioural intelligence in driving simulation scenarios, pp. 201-209.

Duret, A., Leclercq, L., and El Faouzi, N. (2016). "Data assimilation using a mesoscopic Lighthill-Whitham-Richards model and loop detector data: Methodology and large-scale network application". Transportation Research Record: Journal of the Transportation Research Board 2560, pp. 26-35.

Duret, A., Ahn, S., and Buisson, C. (Jan. 2009). "Spatio-temporal analysis of impacts of lane changing consistent with wave propagation". In: Transportation Research Board $88^{\text {th }}$ annual meeting, Compendium of papers. Washington D.C., United States, 16-p.

Edie, L. C. (1961). "Car-Following and Steady-State Theory for Noncongested Traffic”. Operations Research 9.(1), pp. 66-76. 
Ekström, J., Kristoffersson, I., and Quttineh, N.-H. (2016). "Surrogatebased optimization of cordon toll levels in congested traffic networks". Journal of Advanced Transportation 50.(6), pp. 1008-1033.

Enkelmann, W. et al. (2008). PREDRIVE C2X - Deliverable D4.1, Detailed description of selected use-cases and corresponding technical requirements. Tech. rep. Sindelfingen, Germany: European Comission.

Erdmann, J. (2015). "Modeling mobility with open data". In: Modeling Mobility with Open Data. Ed. by M. Behrisch and M. Weber. Cham: Springer International Publishing. Chap. SUMO's Lane-Changing Model, pp. 105-123.

European Commission (2009). Standardisation mandate addressed to CEN, CENELEC and ETSI in the field of information and communication technologies to support the interoperability of co-operative systems for intelligent transport in the European community, 98/34/EC. CEN, CENELEC and ECTRI.

European Commission (2010). European Commission, CORDIS - Collection of European projects. Accessed: October 2010. URL: http: //cordis. europa.eu.

Falcocchio, J. C. and Levinson, H. S. (2015). Road Traffic Congestion. : A Concise Guide. Springer Tracts on Transportation and Traffic. Springer.

Fellendorf, M. and Vortisch, P. (2010). "Microscopic Traffic Flow Simulator VISSIM". In: Fundamentals of Traffic Simulation. Ed. by J. Barceló. New York: Springer, pp. 63-93.

Fernandes, P. and Nunes, U. (Sept. 2010). "Platooning of autonomous vehicles with intervehicle communications in SUMO traffic simulator." In: IEEE Conference on Intelligent Transportation Systems, Proceedings, ITSC'10. Madeira Island, Portugal, pp. 1313-1318.

Frejo, J. R. D., Núñez, A., De Schutter, B., and Camacho, E. F. (2014). "Hybrid model predictive control for freeway traffic using discrete speed 
limit signals". Transportation Research Part C: Emerging Technologies 46, pp. 309-325.

Fritzsche, H. (1994). "A model for traffic simulation”. Traffic Engineering and Control 35, p. 317.

García, C. E., Prett, D. M., and Morari, M. (1989). "Model predictive control: Theory and practice - A survey". Automatica 25.(3), pp. 335348.

Gartner, N. (1983). "OPAC: A demand-responsive strategy for traffic signal control." Transportation Research Record: fournal of the Transportation Research Board 1983.(906), pp. 75-81.

Gee, K. W. (1997). Japan's vehicle crash avoidance research program(s), Observational report. Tech. rep.

Geroliminis, N., Srivastava, A., and Michalopoulos, P. (2011). “A dynamic-zone-based coordinated ramp-metering algorithm with queue constraints for Minnesota's freeways." IEEE Transactions on Intelligent Transportation Systems 12.(4), pp. 1576-1586.

Gipps, P. (1981). "A behavioural car-following model for computer simulation”. Transportation Research Part B: Methodological 15.(2), pp. 105-111.

Gipps, P. (1986). "A model for the structure of lane-changing decisions". Transportation Research Part B: Methodological 20.(5), pp. 403-414.

Gomes, G. and Horowitz, R. (2006). "Optimal freeway ramp metering using the asymmetric cell transmission model". Transportation Research Part C: Emerging Technologies 14, pp. 244-262.

Greenshields, B. D. (Dec. 1934). "The photographic method of studying traffic behavior”. In: Highway Research Board. Vol. 13. Washington DC.

Grumert, E. and Tapani, A. (2018a). "Characteristics of variable speed limit systems". European transport research review. Accepted for publication. 
Grumert, E. and Tapani, A. (2018b). "Non-recurrent bottleneck mitigation through a variable speed limit system using connected vehicles". Transportmetrica A. Submitted.

Grumert, E. and Tapani, A. (2018c). "Traffic state estimation using connected vehicles and stationary detectors". fournal of Advanced Transportation.

Grumert, E. and Tapani, A. (2018d). "Urban motorway bottleneck mitigation - a Stockholm case study”. Case studies on transport policy. Submitted.

Grumert, E., Ma, X., and Tapani, A. (2015). "Analysis of a cooperative variable speed limit system using microscopic traffic simulation”. Transportation Research Part C: Emerging Technologies 52, pp. 173186.

Grumert, F. E. and Tapani, A. (2018e). "Real-time calibration of the parameters in a fundamental diagram using connected vehicles". Transportation Research Part C: Emerging Technologies. Submitted.

Halati, A., Lieu, H., and Walker, S. (June 1997). "CORSIM-corridor traffic simulation model”. In: Traffic Congestion and Traffic Safety in the $21^{\text {st }}$ Century: Challenges, Innovations, and Opportunities, Urban Transportation Division, ASCE; Highway Division, ASCE; Federal Highway Administration, USDOT; and National Highway Traffic Safety Administration, USDOT. Chicago, Illinois United States.

Han, Y., Hegyi, A., Yuan, Y., Hoogendoorn, S., Papageorgiou, M., and Roncoli, C. (2017a). "Resolving freeway jam waves by discrete first-order model-based predictive control of variable speed limits". Transportation Research Part C: Emerging Technologies 77, pp. 405420.

Han, Y., Chen, D., and Ahn, S. (2017b). "Variable speed limit control at fixed freeway bottlenecks using connected vehicles". Transportation Research Part B: Methodological 98, pp. 113-134. 
He, Q, Head, K., and Ding, J (2014). "Multi-modal traffic signal control with priority, signal actuation and coordination". Transportation Research Part C: Emerging Technologies 46, pp. 65-82.

Hegyi, A, De Schutter, B, and Hellendoorn, J (2005). "Optimal coordination of variable speed limits to suppress shock waves". IEEE Transactions on Intelligent Transportation Systems 6.(1), pp. 102-112.

Hegyi, A., Hoogendoorn, S., Schreuder, M., Stoelhorst, H., and Viti, F. (Oct. 2008). "SPECIALIST: A dynamic speed limit control algorithm based on shock wave theory". In: IEEE Conference on Intelligent Transportation Systems, Proceedings, ITSC'08. Beijing, China, pp. 827-832.

Hellinga, B and Mandelzys, M (2011). "Impact of driver compliance on the safety and operational impacts of freeway variable speed limit systems”. fournal of Transportation Engineering 137.(4), pp. 260-268.

Herrera, J. C. and Bayen, A. M. (Jan. 2008). "Traffic flow reconstruction using mobile sensors and loop detector data". In: Transportation Research Board $87^{\text {th }}$ annual meeting, Compendium of papers. Washington D.C., United States.

Herrera, J. C., Work, D. B., Herring, R., Ban, X. J., Jacobson, Q., and Bayen, A. M. (2010). "Evaluation of traffic data obtained via GPS-enabled mobile phones: The Mobile Century field experiment". Transportation Research Part C: Emerging Technologies 18, pp. 568-583.

Herring, R., Hofleitner, A., Abbeel, P., and Bayen, A. (July 2010). "Estimating arterial traffic conditions using sparse probe data". In: IEEE Conference on Intelligent Transportation Systems, Proceedings, ITSC'10. Madeira Island, Portugal, pp. 929-936.

Hidas, P. (2005). "Modelling vehicle interactions in microscopic simulation of merging and weaving". Transportation Research Part C: Emerging Technologies 13.(1), pp. 37-62.

Hoogendoorn, R., van Arem, B., and Hoogendoorn, S. (Oct. 2013). "Incorporating driver distraction in car-following models: Applying 
the TCI to the IDM". In: IEEE Conference on Intelligent Transportation Systems, Proceedings, ITSC'13. Hague, Netherlands.

Hoogendoorn, S. P., Ossen, S., and Schreuder, M. (2006). "Empirics of multianticipative car-following behavior". Transportation Research Record: Journal of the Transportation Research Board 1965, pp. 112120.

IATSS Research (2006). "Transportation and safety in Japan, Advanced Safety Vehicle (ASV) promotion project - third phase". IATSS Research 30.(1).

Ibrahim, A. T. and Hall, F. L. (1994). "Effect of adverse weather conditions on speed-flow-occupancy relationships". Transportation Research Record: Journal of the Transportation Research Board 1457, Part 2, pp. 184-191.

Jabari, S. E. and Liu, H. X. (2013). "A stochastic model of traffic flow: Gaussian approximation and estimation". Transportation Research Part B: Methodological 47, pp. $15-41$.

Jayakrishnan, R, Mahmassani, H. S., and Hu, T.-Y. (1994). “An evaluation tool for advanced traffic information and management systems in urban networks". Transportation Research Part C: Emerging Technologies 2.(3), pp. 129-147.

Jin, H.-Y. and Jin, W.-L. (2015). "Control of a lane-drop bottleneck through variable speed limits." Transportation Research Part C: Emerging Technologies 58, pp. 568-584.

Kattan, L., Khondaker, B., Derushkina, O., and Poosarla, E. (2015). "A Probe-Based Variable Speed Limit System”. Journal of Intelligent Transportation Systems: Technology, Planning, and Operations 19.(4), pp. 339-354.

Kerner, B. S. and Konhäuser, P (1994). "Structure and parameters of clusters in traffic flow”. Physical Review E: Statistical, Nonlinear, and Soft Matter Physics 50.(1), p. 54. 
Kesting, A., Treiber, M., and Helbing, D. (2007). "General lane-changing model MOBIL for car-following models”. Transportation Research Record: Journal of the Transportation Research Board 1999, pp. 86-94.

Khondaker, B. and Kattan, L. (2015a). "Variable speed limit: an overview”. Transportation Letters 7.(5), pp. 264-278.

Khondaker, B. and Kattan, L. (2015b). "Variable speed limit: A microscopic analysis in a connected vehicle environment". Transportation Research Part C: Emerging Technologies 58, pp. 146-159.

Kita, H. (1999). "A merging-giveway interaction model of cars in a merging section: a game theoretic analysis". Transportation Research Part A: Policy and Practice 33.(3), pp. 305-312.

Knoop, V. L. and Daamen, W. (2017). "Automatic fitting procedure for the fundamental diagram”. Transportmetrica B: Transport Dynamics 5.(2), pp. 129-144.

Knoop, V., Hoogendoorn, S., and Van Zuylen, H. (2008). "Capacity reduction at incidents: Empirical data collected from a helicopter". Transportation Research Record: fournal of the Transportation Research Board 2071, pp. 19-25.

Krajzewicz, D. (2011). "Traffic simulation with SUMO - Simulation of Urban Mobility". In: Fundamentals of traffic simulation. Ed. by J. Barceló. Vol. 145. International series in operations research \& management science. Springer. Chap. 8, pp. 269-293.

Krajzewicz, D. et al. (June 2005). "Simulation of modern traffic lights control systems using the open source traffic simulation SUMO.” In: Industrial simulation conference: ISC'2005. Berlin, Germany, pp. 299304.

Krajzewicz, D. (May 2013). "Summary on Publications citing SUMO, 2002-2012". In: Proceedings of the $1^{\text {st }}$ SUMO User Conference, SUMO 2013. Vol. 21. Berlin, Germany, pp. 11-24. 
Krajzewicz, D., Erdmann, J., Behrisch, M., and Bieker, L. (2012). "Recent Development and Applications of SUMO - Simulation of Urban MObility". International fournal On Advances in Systems and Measurements 5.(3\&4), pp. 128-138.

Krauß, S. (1998). "Microscopic modeling of traffic flow: Investigation of collision free vehicle dynamics". PhD Thesis. Mathematisches Institut, Universität zu Köln, Germany: Hauptabteilung Mobilität und Systemtechnik des DLR Köln.

Kurkjian, A., Gershwin, S. B., Houpt, P. K., Willsky, A. S., Chow, E. Y., and Greene, G. S. (1980). "Estimation of Roadway Traffic Density on Freeways Using Presence Detector Data”. Transportation Science 14.(3), p. 232.

Laberteaux, K. (2006). C2C-CC Security Workshop, Presentation: Session No. 2 - Requirements / International Perspectives - CAMP / U.S. Perspective (Slideset 2). Accessed: November 2010. URL: http://www. car2-car.org/index. php?id=39\&L=hmbprmsrbrjdev.

Laval, J. A. and Daganzo, C. F. (2006). "Lane-changing in traffic streams". Transportation Research Part B: Methodological 40, pp. 251-264.

Lee, C, Hellinga, B, and Saccomanno, F (2004). "Assessing safety benefits of variable speed limits: Statistical methods and safety data analysis and evaluation". Transportation Research Record: Fournal of the Transportation Research Board 1897, pp. 183-190.

Lee, C., Hellinga, B., and Saccomanno, F. (2006). "Evaluation of variable speed limits to improve traffic safety". Transportation Research Part C: Emerging Technologies 14.(3), pp. 213-228.

Lenz, H., Wagner, P., and Sollacher, R. (1999). "Multi-anticipative carfollowing model”. European Physical fournal B: Condenced Matter and Complex Systems 7.(2), pp. 331-335.

Leonard, D., Gower, P., and Taylor, N. (1989). CONTRAM: Structure of the Model. Vol. 78. 
Li, D. and Ranjitkar, P. (2015). "A fuzzy logic-based variable speed limit controller”. Fournal of Advanced Transportation 49.(8), pp. 913-927.

Li, D., Ranjitkar, P., and Ceder, A. (Jan. 2014a). "A logic tree based algorithm for variable speed limit controllers to manage recurrently congested bottlenecks". In: Transportation Research Board 93 ${ }^{\text {rd }}$ Annual Meeting, Compendium of papers. Washington D.C., United States.

Li, Z., Liu, P., Wang, W., and Xu, C. (2014b). "Development of a control strategy of variable speed limits to reduce rear-end collision risks near freeway recurrent bottlenecks". IEEE Transactions on Intelligent Transportation Systems 15.(2), pp. 866-877.

Liang, X. R. and Wang, D. Q. (2012). "Design and Simulation of Speed Limit Controller Based on Fuzzy Logic Inference”. Applied Mechanics and Materials 220, pp. 988-991.

Lighthill, M. and Whitham, J. (1955). "On kinematic waves. II. A theory of traffic flow on long crowded roads". Proceedings of the royal society of London. Series A, mathematical and physical sciences 229.(1178), pp. 317-345.

Lockwood, S. (2005). "Systems Management and Operations: A Culture Shock”. Institute of Transportation Engineers (ITE) Journal 75.(5), pp. 43-47.

Lu, X.-Y. and Shladover, S. (2014). "Review of variable speed limits and advisories: Theory, algorithms, and practice". Transportation Research Record: Fournal of the Transportation Research Board 2423, pp. 15-23.

Lu, X.-Y., Varaiya, P., Horowitz, R., Su, D., and Shladover, S. (2011). "Novel Freeway Traffic Control with Variable Speed Limit and Coordinated Ramp Metering”. Transportation Research Record: fournal of the Transportation Research Board 2229, pp. 55-65. 
Ma, Y., Van Dalen, J., Kroon, L., and De Blois, C. (2011). "Estimation of dynamic traffic densities for official statistics". Transportation Research Record: fournal of the Transportation Research Board 2256.

Maunsell, F. and Parkman, M. (2007). M25, Control motorway, Summary report. Tech. rep. London, United Kingdom: Department for transportation.

May, A. D. (1990). Traffic flow fundamentals. Prentice Hall.

Meng, Q. and Khoo, H. L. (2010). "A Pareto-optimization approach for a fair ramp metering". Transportation Research Part C: Emerging Technologies 18.(4), pp. 489-506.

Messner, A. and Papageorgiou, M (1990). "METANET: a macroscopic simulation program for motorway networks". Traffic Engineering and Control 31.(9), pp. 466-470.

Mihaylova, L, Boel, R, and Hegyi, A (2007). "Freeway traffic estimation within particle filtering framework.” Automatica 43.(2), pp. 290-300.

Mirchandani, P. and Head, L. (2001). "A real-time traffic signal control system: architecture, algorithms, and analysis". Transportation Research Part C: Emerging Technologies 9.(6), pp. 415-432.

Montero, L., Pacheco, M., Barceló J. nad Homoceanu, S., and Casanovas, J. (Jan. 2016). "A case study on cooperative car data for traffic state estimation in an urban network". In: Transportation Research Board 95 ${ }^{\text {rd }}$ Annual Meeting, Compendium of papers. Washington D.C., United States.

Morari, M. and Lee, J. H. (1999). "Model predictive control: past, present and future”. Computers \& Chemical Engineering 23.(4-5), pp. 667682 .

Moridpour, S., Sarvi, M., Rose, G., and Mazloumi, E. (2012). "Lanechanging decision model for heavy vehicle drivers". fournal of Intelligent Transportation Systems: Technology, Planning, and Operations 16.(1), pp. 24-35. 
Muñoz, L., Sun, X., Horowitz, R., and Alvarez, L. (June 2003). "Traffic density estimation with the cell transmission model." In: IEEE American Control Conference ACC'03. Vol. 5. denver, United States, pp. 3750-3755.

Müller, E. R., Carlson, R. C., Kraus, W., and Papageorgiou, M. (2015). "Microsimulation analysis of practical aspects of traffic control with variable speed limits". IEEE Transactions on Intelligent Transportation Systems 16.(1), pp. 512-523.

Müller, E. R., Carlson, R. C., and Kraus, W. (2016). "Cooperative Mainstream Traffic Flow Control on Freeways". IFAC-PapersOnLine 49.(32), pp. 89-94.

Newell, G. (2002). "A simplified car-following theory: a lower order model”. Transportation Research Part B: Methodological 36.(3), pp. 195-205.

Nissan, A. and Bang, K. L. (Sept. 2006). "Evaluation of impacts of the motorway control system (MCS) in Stockholm". In: European Transport Conference (ETC) Association for European Transport. Strasbourg, France.

Nissan, A. and Koutsopoulos, H. N. (2011). "Evaluation of the Impact of Advisory Variable Speed Limits on Motorway Capacity and Level of Service”. Procedia - Social and Behavioral Sciences 16, pp. 100-109.

OECD International transport forum (2017). ITF Transport Outlook 2017. Tech. rep.

Ossen, S. and Hoogendoorn, S. P. (2011). "Heterogeneity in carfollowing behavior: Theory and empirics". Transportation Research Part C: Emerging Technologies 19, pp. 182-195.

Ozbay, K., Yasar, I., and Kachroo, P. (Sept. 2006). "Improved online estimation methods for a feedback-based freeway ramp metering strategy". In: IEEE Conference on Intelligent Transportation Systems, Proceedings, ITSC'06. Toronto, Canada, pp. 412-417. 
Pan, J., Khan, M. A., Popa, I. S., Zeitouni, K., and Borcea, C. (May 2012). "Proactive vehicle re-routing strategies for congestion avoidance". In: IEEE $8^{\text {th }}$ International Conference on Distributed Computing in Sensor Systems (DCOSS). Hangzhou, China, pp. 265-272.

Papageorgiou, M., Hadj-Salem, H., and Blosseville, J.-M. (1991). "ALINEA: A local feedback control law for on-ramp metering". Transportation Research Record: Journal of the Transportation Research Board 1320, pp. 58-64.

Piao, J. and McDonald, M. (Oct. 2008). "Safety impacts of variable speed limits - A simulation study." In: IEEE Conference on Intelligent Transportation Systems, Proceedings, ITSC'08. Beijing, China, pp. 833-837.

Pipes, L. A. (1967). "Car following models and the fundamental diagram of road traffic”. Transportation Research 1.(1), pp. 21 -29.

Qiu, T., Lu, X.-Y., Chow, A., and Shladover, S. (2010). "Estimation of freeway traffic density with loop detector and probe vehicle data". Transportation Research Record: Journal of the Transportation Research Board 2178.

Qu, X., Wang, S., and Zhang, J. (2015). "On the fundamental diagram for freeway traffic: A novel calibration approach for single-regime models." Transportation Research Part B: Methodological 73, pp. 91 -102 .

Qu, X., Zhang, J., and Wang, S. (2017). "On the stochastic fundamental diagram for freeway traffic: Model development, analytical properties, validation, and extensive applications". Transportation Research Part B: Methodological 104, pp. 256-271.

Rahman, M., Chowdhury, M., Xie, Y., and He, Y. (2013). "Review of microscopic lane-changing models and future research opportunities". IEEE Transactions on Intelligent Transportation Systems 14.(4), pp. 1942-1956. 
Ranjitkar, P., Nakatsuji, T., and Kawamua, A. (2005). "Car-following models: An experiment based on benchmarking". Journal of the Eastern Asia Society for Transportation Studies 6, pp. 1582-1596.

Rickert, M., Nagel, K., Schreckenberg, M., and Latour, A. (1996). "Two lane traffic simulations using cellular automata”. Physica A: Statistical Mechanics and its Applications 231.(4), pp. 534-550.

Safespot (2010). Homepage: Safespot. Accessed: October 2010. URL: http://www. safespot-eu.org/.

Schakel, W., Knoop, V., and Arem, B. van (2012). "Integrated lane change model with relaxation and synchronization". Transportation Research Record: fournal of the Transportation Research Board 2316, pp. 47-57.

Schulze, M., Kosch, T., Kulp, I., Benz, T., Tomatis, A., Radusch, I., Noecker, G., Andreone, L., Kessel, T., and Klessen, C. (2010). Deliverable D0.3 Final report: preparation for driving implementation and evaluation of C2X communication technology, PRE-DRIVE C2X. Tech. rep. Sindelfingen, Germany: European Commission.

Schulze, M. (2006). Workshop on Spectrum Requirements for Road Safety, Brussels, Presentation: International Initiatives, Europe in Comparison to USA and Japan. Accessed: November 2010. URL: http://ec . europa . eu / information_society / activities / esafety / before/2006/index_en.htm.

Schumacher, H., Schack, M., and Kürner, T. (Dec. 2009). "Coupling of simulators for the investigation of car-to-X communication aspects." In: IEEE Asia-Pacific Services Computing Conference, APSCC 2009. Biopolis, Singapore, pp. 58-63.

Seo, T. and Kusakabe, T. (2015). "Probe vehicle-based traffic state estimation method with spacing information and conservation law". Transportation Research Part C: Emerging Technologies 59, pp. 391403. 
Seo, T., Kusakabe, T., and Asakura, Y. (2015a). "Estimation of flow and density using probe vehicles with spacing measurement equipment". Transportation Research Part C: Emerging Technologies 53, pp. 134150.

Seo, T., Kusakabe, T., and Asakura, Y. (Sept. 2015b). “Traffic State Estimation with the Advanced Probe Vehicles Using Data Assimilation". In: IEEE Conference on Intelligent Transportation Systems, Proceedings, ITSC'15. Canary Islands, Spain, pp. 824-830.

Seo, T., Bayen, A. M., Kusakabe, T., and Asakura, Y. (2017). "Traffic state estimation on highway: A comprehensive survey". Annual Reviews in Control 43, pp. 128-151.

Shulman, M. (2009). Intelligent Vehicle Technology Transfer workshop, Presentation 10 - Shulman Ford IntelliDrive Safety. Accessed: November 2010. URL: http://www . intelligent-vehicle.com/index . php/events-workshop-2009.

Shulman, M. and Deering, R. K. (2004). Second Annual Report of the Crash Avoidance Metrics Partnership, April 2002 - March 2003. Tech. rep. (DOT HS 809 663). Washington D.C., United States: National Highway Traffic Safety Administration.

Singh, K. and Li, B. (Nov. 2012). "Estimation of Traffic Densities for Multilane Roadways Using a Markov Model Approach". IEEE Transactions on Industrial Electronics 59.(11), pp. 4369-4376.

Smaragdis, E., Papageorgiou, M., and Kosmatopoulos, E. (2004). "A flowmaximizing adaptive local ramp metering strategy". Transportation Research Part B: Methodological 38.(3), pp. 251-270.

Smulders, S. and Helleman, D. (Apr. 1998). "Variable speed control: State-of-the-art and synthesis." In: $9^{\text {th }}$ International Conference on Road Transport Information and Control. (454). London, UK, pp. 155159.

Sommer, C., Yao, Z., German, R., and Dressler, F. (Apr. 2008). "Simulating the influence of IVC on road traffic using bidirectionally 
coupled simulators." In: Proceedings - IEEE Infocom. Phoenix, Arizona, United States.

Soriguera, F., Torné, J. M., and Rosas, D. (2013). “Assessment of Dynamic Speed Limit Management on Metropolitan Freeways". Fournal of Intelligent Transportation Systems: Technology, Planning, and Operations 17.(1), pp. 78-90.

Soriguera, F., Martínez, I., Sala, M., and Menéndez, M. (2017). "Effects of low speed limits on freeway traffic flow". Transportation Research Part C: Emerging Technologies 77, pp. 257-274.

Srinivasan, D., Choy, M. C., and Cheu, R. L. (2006). "Neural Networks for Real-Time Traffic Signal Control”. IEEE Transactions on Intelligent Transportation Systems 7.(3), pp. 261-272.

Srivastava, A. and Geroliminis, N. (2013). "Empirical observations of capacity drop in freeway merges with ramp control and integration in a first-order model". Transportation Research Part C: Emerging Technologies 30, pp. 161-177.

Sykes, P. (2010). "Traffic Simulation with Paramics". In: Fundamentals of Traffic Simulation. Ed. by J. Barceló. New York: Springer, pp. 131171.

Tampère, C. and Immers, L. (Oct. 2007). "An extended kalman filter application for traffic state estimation using CTM with implicit mode switching and dynamic parameters". In: IEEE Conference on Intelligent Transportation Systems, Proceedings, ITSC'07. Begium, Europe, pp. 209-216.

Tang, T., Shi, W., Shang, H., and Wang, Y. (2014). "A new car-following model with consideration of inter-vehicle communication". Nonlinear Dynamics 76.(4), pp. 2017-2023.

Taylor, N. B., Nitsche, P., Rooij, L. van, Bernhardsson, V., Mocanu, I., and Olstam, J. (2015). PRIMA (Pro-active incident management ): Report on best practice, needs and derived incident scenario, Deliverable D2.2. 
Tech. rep. CEDR Transnational Road Research Programme, Call 2013: Traffic Management.

The VII Consortium (2009). Final Report:Vehicle Infrastructure Integration, Proof of Concept Technical Description - Vehicle. Tech. rep. US Department of Transportation.

Toledo, T., Koutsopoulos, H., and Ben-Akiva, M. (2003). "Modeling integrated lane-changing behavior". Transportation Research Record: fournal of the Transportation Research Board 1857, pp. 30-38.

Toledo, T., Koutsopoulos, H. N., and Ben-Akiva, M. (2007). "Integrated driving behavior modeling”. Transportation Research Part C: Emerging Technologies 15.(2), pp. 96-112.

Tomar, R. S., Verma, S., and Tomar, G. S. (Nov. 2010). "Prediction of lane change trajectories through neural network". In: IEEE International conference on computational intelligence and communication networks (CICN). Bhopal, India, pp. 249-253.

Torday, A., Casas, J., Aymami, J., and Gerodimos, A. (June 2011). "Evaluating the efficiency of variable speed policies using microsimulation". In: The $11^{\text {th }}$ Asia-Pacific ITS Forum \& Exibition. Kaohsiung, Taiwan.

Treiber, M., Hennecke, A., and Helbing, D. (2000). "Congested traffic sstate in empirical observations and microscopic simulations". Physical Review E: Statistical, Nonlinear, and Soft Matter Physics 62.(2), pp. 1805-1824.

Treiber, M. and Kesting, A. (2013). Traffic flow dynamics: Data, models and simulation. Springer.

Treiber, M., Kesting, A., and Helbing, D. (2005). "Delays, inaccurancies and anticipation in microscopic traffic models". Physica A: Statistical Mechanics and its Applications 360.(1), pp. 71-88.

U.S. DOT (2009). IntelliDriveSM Governance Needs Summary, A Summarization of Research from 2004-2009. Tech. rep. Washigton D.C., United States: U.S. Department of Transportation. 
van Aerde, M. and Rakha, H. (Aug. 1995). "Multivariate calibration of single regime speed-flow-density relationships". In: IEEE Vehicle Navigation and Information Systems Conference. Washington D. C., United States, pp. 334-341.

van den Hoogen, E. and Smulders, S. (Apr. 1994). "Control by variable speed signs. Results of the Dutch experiment”. In: $7^{\text {th }}$ International Conference on Road Traffic Monitoring and Control. London, UK, pp. 145-149.

van Lint, H. and Djukic, T. (2014). "Applications of Kalman filtering in traffic management and control". In: New Directions in Informatics, Optimization, Logistics, and Production. INFORMS, pp. 59-91.

van Lint, J. W. C. and Hoogendoorn, S. P. (2010). "A Robust and Efficient Method for Fusing Heterogeneous Data from Traffic Sensors on Freeways." Computer-Aided Civil \& Infrastructure Engineering 25.(8), pp. 596-612.

van Toorenburg, J. A. C. and de Kok, M. L. (1999). Automatic incident detection in the motorway control system MTM. Tech. rep. Bureau Transpute, Gouda, Holland.

VICS (2010). Homepage: VICS. Accessed: November 2010. URL: http: //www.vics.or.jp/english/vics/index.html.

Wang, H., Li, J., Chen, Q.-Y., and Ni, D. (Jan. 2010). "Representing the Fundamental Diagram: the Pursuit of Mathematical Elegance and Empirical Accuracy". In: Transportation Research Board $89^{\text {th }}$ Annual Meeting, Compendium of papers. Washington D.C., United States.

Wang, H., Ni, D., Chen, Q.-Y., and Li, J. (2013). "Stochastic modeling of the equilibrium speed-density relationship". Fournal of Advanced Transportation 47.(1), pp. 126-150.

Wang, R., Work, D., and Sowers, R. (2016). "Multiple Model Particle Filter for Traffic Estimation and Incident Detection”. IEEE Transactions on Intelligent Transportation Systems 17.(12), p. 3461. 
Wang, S., Djahel, S., and McManis, J. (Oct. 2014). "A multi-agent based vehicles re-routing system for unexpected traffic congestion avoidance". In: IEEE Conference on Intelligent Transportation Systems, Proceedings, ITSC'14. Qingdao, China, pp. 2541-2548.

Wang, Y. and Papageorgiou, M. (2005). "Real-time freeway traffic state estimation based on extended Kalman filter: a general approach". Transportation Research Part B: Methodological 39.(2), pp. 141-167.

Wang, Y., Papageorgiou, M., Messmer, A., Coppola, P., Tzimitsi, A., and Nuzzolo, A. (2009). "An adaptive freeway traffic state estimator". Automatica 45.(1), pp. 10-24.

Wani, K. (2006). 13th ITS World Congress SS59 and SS64 (ExCel London,London,UK), Presentation: The Fourth Phase of Advanced Safety Vehicle Project. Accessed: November 2010. URL: http://www . itsforum.gr.jp/Public/E4Meetings/.

Wiedemann, R. and Reiter, U. (1992). Microscopic traffic simulation: the simulation system MISSION, background and actual state. Final report (vol. 2, Appedix A). Brussels: CEC: Project ICARUS (V1052).

Work, D. B., Blandin, S., Tossavainen, O.-P., Piccoli, B., and Bayen, A. M. (2010). "A traffic model for velocity data assimilation". Applied Mathematics Research eXpress 2010.(1), pp. 1-35.

Wu, J., Brackstone, M., and McDonald, M. (2000). "Fuzzy sets and systems for a motorway microscopic simulation model”. Fuzzy sets and systems 116.(1), pp. 65-76.

Wu, N. (2002). "A new approach for modeling of Fundamental Diagrams”. Transportation Research Part A: Policy and Practice 36.(10), pp. $867-884$.

Yang, H. and Jin, W.-L. (2014). "A control theoretic formulation ofgreen driving strategies based on inter-vehicle communications". Transportation Research Part C: Emerging Technologies 41, pp. 48-60. 
Yuan, Y., Van Lint, H, Van Wageningen-Kessels, F, and Hoogendoorn, S (2014). "Network-Wide Traffic State Estimation Using Loop Detector and Floating Car Data". Journal of Intelligent Transportation Systems: Technology, Planning, and Operations 18.(1), pp. 41-50.

Zegeye, S. K., De Schutter, B., Hellendoorn, H., and Breunesse, E. (June 2009). "Reduction of travel times and traffic emissions using model predictive control”. In: IEEE American Control Conference ACC'09. St. Louis, MO, United States.

Zegeye, S., De Schutter, B., Hellendoorn, J., and Breunesse, E. (July 2011). "Reduction of area-wide emissions using an efficient model-based traffic control strategy". In: IEEE Forum on Integrated and Sustainable Transportation Systems, FISTS. Vienna, Austria, pp. 239-244.

Zhang, J., He, S., Wang, W., and Zhan, F. (2015). “Accuracy Analysis of Freeway Traffic Speed Estimation Based on the Integration of Cellular Probe System and Loop Detectors". Fournal of Intelligent Transportation Systems: Technology, Planning, and Operations 19.(4), pp. 411-426.

Zhang, J., Chang, H., and Ioannou, P. A. (June 2006). "A Simple Roadway Control System for Freeway Traffic". In: IEEE American Control Conference ACC'06. Minnesota, USA, pp. 4900-4905.

Zhang, L. and Levinson, D. (2004). "Some properties of flows at freeway bottlenecks". Transportation Research Record: Journal of the Transportation Research Board 1883, pp. 122-131.

Zhang, Y. and Ioannou, P. (2016). "Combined Variable Speed Limit and Lane Change Control for Highway Traffic”. IEEE Transactions on Intelligent Transportation Systems 18.(7), pp. 1812-1823.

Zhicai, J., Xiaoxiong, Z., and Hongwei, Y. (Oct. 2004). "Simulation research and implemented effect analysis of variable speed limits on freeway". In: IEEE Conference on Intelligent Transportation Systems, Proceedings, ITSC'04. Washington, United States, pp. 894-898. 
Zhong, R., Chen, C., Chow, A. H. F., Pan, T., Yuan, F., and He, Z. (2016). "Automatic calibration of fundamental diagram for first-order macroscopic freeway traffic models." Fournal of Advanced Transportation 50.(3), pp. $363-385$.

Zubillaga, D., Cruz, G., Aguilar, L. D., Zapotécatl J.catl, J., Fernández, N., Aguilar, J., Rosenblueth, D. A., and Gershenson, C. (2014). "Measuring the Complexity of Self-Organizing Traffic Lights”. Entropy 16.(5), pp. 2384-2407. 


\section{Papers}

The papers associated with this thesis have been removed for copyright reasons. For more details about these see:

http://urn.kb.se/resolve?urn=urn:nbn:se:liu:diva-147049 